\title{
New interpretation of the cranial osteology of the Early Cretaceous turtle Arundelemys dardeni (Paracryptodira) based on a CT-based re-evaluation of the holotype
}

\author{
Serjoscha W Evers ${ }^{\text {Corresp., }}{ }^{1}$, Yann Rollot ${ }^{1}$, Walter G Joyce ${ }^{1}$ \\ ${ }^{1}$ Department of Geosciences, University of Fribourg, Fribourg, Switzerland \\ Corresponding Author: Serjoscha W Evers \\ Email address: serjoscha.evers@googlemail.com
}

Arundelemys dardeni is an Early Cretaceous paracryptodire known from a single, incomplete, but generally well-preserved skull. Phylogenetic hypotheses of paracryptodires often find Arundelemys dardeni as an early branching baenid. As such, it has a central role in understanding the early evolution of the successful clade Baenidae, which survived the Cretaceous-Paleogene mass extinction, as well as the diversification of Paracryptodira into its subclades, which recent research suggests to perhaps include helochelydrids, compsemydids, pleurosternids, and baenids. Computer tomography scans of the holotype material that were produced for the initial description of Arundelemeys dardeni reveal several errors in the initial anatomical description of the species, which we correct based on element-by-element segmentation. In addition, we provide entirely novel anatomical information, including descriptions of several previously undescribed cranial bones, the endosseous labyrinth, and the cranial scutes, the latter of which are unknown for most paracryptodires. We provide an interpretation of cranial scutes which homologizes the scutes of Arundelemys dardeni with those of other stem turtles. 


\section{New interpretation of the cranial osteology of the}

\section{Early Cretaceous turtle Arundelemys dardeni}

\section{3 (Paracryptodira) based on a CT-based re-evaluation of}

\section{4 the holotype}

5

6 Serjoscha W. Evers ${ }^{1}$, Yann Rollot ${ }^{1}$ and Walter G. Joyce ${ }^{1}$

7

$8{ }^{1}$ Department of Geosciences, University of Fribourg, Fribourg, Switzerland

9

10 Corresponding Author:

11 Serjoscha W. Evers ${ }^{1}$

12 Chemin de Musée 6, 1700 Fribourg, Switzerland

Email address: serjoscha.evers@unifr.ch

\section{ABSTRACT}

Arundelemys dardeni is an Early Cretaceous paracryptodire known from a single, incomplete,

but generally well-preserved skull. Phylogenetic hypotheses of paracryptodires often find

Arundelemys dardeni as an early branching baenid. As such, it has a central role in

understanding the early evolution of the successful clade Baenidae, which survived the

Cretaceous-Paleogene mass extinction, as well as the diversification of Paracryptodira into its subclades, which recent research suggests to perhaps include helochelydrids, compsemydids, 
22 pleurosternids, and baenids. Computer tomography scans of the holotype material that were

23 produced for the initial description of Arundelemeys dardeni reveal several errors in the initial

24 anatomical description of the species, which we correct based on element-by-element

25 segmentation. In addition, we provide entirely novel anatomical information, including

26 descriptions of several previously undescribed cranial bones, the endosseous labyrinth, and the

27 cranial scutes, the latter of which are unknown for most paracryptodires. We provide an

28 interpretation of cranial scutes which homologizes the scutes of Arundelemys dardeni with those

29 of other stem turtles.

30

31 Key words: Testudines, Paracryptodira, Baenidae, cranial scutes, turtles

33 INTRODUCTION

34 Ardundelemys dardeni was originally described on the basis of a single, partial cranium by Lipka

35 et al. (2006). These authors also described the cranial anatomy with reference to computed

36 tomography (CT) scans, albeit without providing element-by-element segmentations of the

37 specimen (USNM 497740). As was common at the time, the descriptions in Lipka et al. (2006)

38 were kept relatively brief and some cranial elements (e.g. prootics, opisthotic, exoccipital) were

39 not described at all, despite being preserved. Based on a number of traits, such as the positioning

40 of the foramen for the internal carotid artery, Lipka et al. (2006) identified Arundelemys dardeni

41 as an early branching paracryptodire, but most phylogenetic analyses have since retrieved this

42 species as an early baenid (Lyson et al., 2011, 2016; Lyson \& Joyce, 2011; Larson et al., 2013;

43 Lively, 2015; Pérez-García et al., 2015; Smith et al., 2017; Joyce \& Rollot 2020; Rollot, Evers \&

44 Joyce, in press). As part of an on-going project to better understand paracryptodire anatomy, 
45 systematics, and evolution, we recently (re-)described the cranial anatomy of Eubaena cephalica

46 (Rollot, Lyson \& Joyce, 2018), Pleurosternon bullockii (Evers, Rollot \& Joyce, 2020) and

47 Uluops uluops (Rollot, Evers \& Joyce, in press). During this work, we found a number of

48 discrepancies between the published anatomy of Arundelemys dardeni with our own perceptions

49 of the anatomy of the specimen, which led us to produce a full cranial segmentation of the

50 holotype material on the basis of the CT scan already used in the initial study. Here, we present

51 the resulting cranial models, and provide a re-description of the cranial anatomy of Arundelemys

52 dardeni that corrects some errors of the previous work of Lipka et al. (2006), which, for the most

53 part, remains an accurate account of the gross morphology of the material. Although our

54 observations provide novel anatomical information and detail that could inform paracryptodire

55 phylogeny, we only provide a description of Arundelemys dardeni without further phylogenetic

56 work, as we are currently preparing a comprehensive phylogenetic analysis for the group.

57

58 MATERIAL \& METHODS

59 We used the high-resolution X-ray computed tomography (CT) scans of USNM 497740

60 produced by Lipka et al. (2006) for our segmentations. These data are available on the online

61 repository Digimorph, where Matthew Colbert is indicated as the person who obtained the scans

62 at the University of Texas in Austin in 2004. The specimen was scanned at a beam energy of 180

$63 \mathrm{kV}$, a current of $0.133 \mathrm{~mA}$, and without using a filter. The voxel size data for the scan are non-

64 isotropic, with $\mathrm{x}$ and y pixels being $0.04346 \mathrm{~mm}$, and the interslice spacing in the $\mathrm{z}$-plane

65 (coronal plane) being $0.09457 \mathrm{~mm}$. The resulting CT-scans were segmented in the software

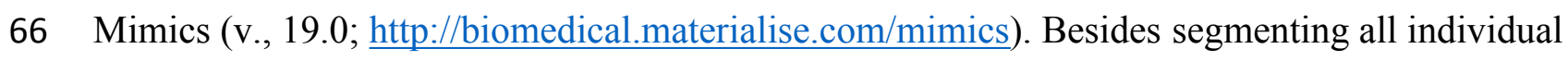

67 bones, we segmented the left labyrinth, as well as the paths of the carotid arteries and selected 
68 cranial nerves of USNM 497740. 3D models were exported as .ply files. Figures of digital

69 renderings were compiled using the software Blender v. 2.71 (blender.org). CT-slice data as well

70 as the 3D models are deposited at MorphoSource (Evers, 2021). The comparative 3D models of

71 Uluops uluops are also digitally available at MorphoBank (Rollot, Evers \& Joyce, in press;

72 http://morphobank.org/permalink/?P3919).

73

\section{SYSTEMATIC PALAEONTOLOGY}

75

76

TESTUDINATA Klein, 1760

77 PARACRYPTODIRA Gaffney, 1975

78 ARUNDELEMYS Lipka et al., 2006

79 Arundelemys dardeni Lipka et al., 2006

80

81 Holotype: USNM 497740, a nearly complete cranium.

82 Type locality and horizon: USNM locality 41614 (Hotton locality), an open-pit clay mine near

83 Muirkirk, Maryland, USA; Potomac Formation, Early Cretaceous, late Albian-early Aptian. See

84 Lipka et al. (2006) for additional geological information.

85 Revised diagnosis: Arundelemys dardeni can be diagnosed as a member of Paracryptodira based

86 on the presence of a characteristic combination of derived and symplesiomorphic features. These

87 include the presence of skull sculpturing (also present in some sinemydids; Brinkman \& Peng,

88 1993; Zhou, Rabi \& Joyce, 2014; and some xinjiangchelyids: Tong et al., 2019); a relatively

89 strong lateral orbit orientation; the retention of relatively large nasals paired with their partial

90 posterior separation by the anterior frontal processes (the nasals of early Testudinata or 
91 Meiolaniformes are in medial contact with one another across their entire length: Gaffney, 1990;

92 Sterli, 2015; and the nasals of sinemydids are small: e.g. Rabi et al., 2013; Li et al., 2019); a

93 unique combination of jugal features that includes a dorsally raised jugal position (as in

94 xinjiangchelyids, but unlike in meiolaniforms; varies in sinemydids: see Brinkman \& Wu 1999;

95 Li et al., 2019) and its exclusion from the orbital margin (unlike in sinemydids, xinjiangchelyids,

96 meiolaniforms); retention of a posteriorly open incisura columella auris; and a unique

97 combination of traits surrounding the embedding of the carotid artery, including the presence of

98 a carotid pit, absence of internal carotid artery embedding, and the absence of a palatine artery

99 canal or interpterygoid vacuity indicating the reduction of the respective artery (retained in

100 Uluops uluops among paracryptodires: Rollot, Evers \& Joyce, in press). A distinct lingual ridge

101 that is better developed along the anterior half of the palate, a ventral process of the jugal that

102 nearly contributes to the labial margins, and an expanded posterior process of the pterygoid that

103 contacts the basioccipital and exoccipital are characteristics typical of baenids, but the potential

104 baenid affinities of Arundelemys dardeni should be tested in a phylogenetic analysis.

105

106 DESCRIPTION

107 General comments. Although differences in interpretation between our study and that of Lipka 108 et al. (2006) are pointed out individually in the respective description sections below, the reader 109 shall note that our biggest re-interpretations of morphology concern (i) the preservation of the 110 temporal roof and supraoccipital, which we interpret to be far less complete; (ii) the morphology

111 of the anterior end of the pterygoids, which we interpret as forming extended anterior processes

112 rather than forming a straight transverse suture with the anterior part of the palate (Fig. 1); (iii) 
113 the shape, position and contacts of the epipterygoid (Fig. 1); and (iv) the placement of the

114 foramina anterius canalis carotici basisphenoidalis.

115 The skull surface of USNM 497740 is weakly sculptured by low and irregular pits (Lipka et

116 al., 2006), which are present across all skull roof and temporal bone elements as well as the

117 maxilla. This texture is similar to that in Trinitichely hiatii (pers. obs.), but distinct from the

118 dense tubercular pattern in Uluops uluops (Rollot, Evers \& Joyce, in press), the fine crenulations

119 in Dorsetochelys typocardium (DORCM G 23), or the striated pattern of Pleurosternon bullockii

120 (Evers, Rollot \& Joyce, 2020). Overall, the sculpturing in Arundelemys dardeni is less uniform,

121 less dense, and less strongly structured than in other early paracryptodires.

122 In addition to surface sculpturing, several scute sulci can be traced across the skull roof of

123 USNM 497740 (Fig. 2). These were mentioned by Lipka et al. (2006), but not described. The

124 sulci are relatively broad but low grooves spread across the dermal skull roof, but only few sulci

125 can be followed for their full extent. In the 3D models, they can best be appreciated with low

126 light/at low angles and when rotating the specimen. For ease of communication about individual

127 scutes, we applied the scute nomenclatural system of Sterli and de la Fuente (2013). This system

128 was developed as a homology hypothesis of scutes, and has primarily been applied to compare

129 the scute patterns of early shelled turtles, including Proganochelys quenstedtii, with

130 meiolaniforms (Sterli \& de la Fuente, 2013, Sterli, 2015), but has since been used for turtles of

131 other clades as well (e.g. Rabi et al., 2013, 2014; Li et al., 2019). In this context, it is important

132 to note that the concept presented in Sterli and de la Fuente (2013: their fig. 10) seems to have an

133 inconsistency regarding the identification of scutes H and D. Specially, scutes H and D are

134 switched in panel C (Meiolania platyceps) with regard to all other turtles shown. In particular,

135 whereas the D scute is anteroventrally in contact with the F scute series and covers the parietal- 
136 postorbital region in all other turtles (including other derived meiolaniids), the respective scute in

137 Meiolania platyceps is labelled as 'H' (Sterli \& de la Fuente, 2013: their fig. 10). The scute

138 posterolaterally to this position is the $\mathrm{H}$ scute in all other turtles, but labelled as ' $\mathrm{D}$ ' in Meiolania

139 platyceps. The pattern of Meiolania platyceps used by Sterli \& de la Fuente (2013) is identical to

140 that used by Gaffney (1983), which itself is based on Simpson (1938). Thus, the scute

141 identification for Meiolania platyceps has historical roots, and it is unfortunate that the

142 Meiolania-pattern has apparently been incorrectly applied to the other turtles shown by Sterli \&

143 de la Fuente (2013). If this Meiolania-based nomenclature were given priority, all other taxa

144 shown by Sterli \& de la Fuente (2013; their fig. 10) as well as all following publications which

145 identified cranial scutes in turtles (e.g. Rabi et al., 2013, 2014; Li et al., 2019) would be in

146 consecutive error. We find it easier to correct this discrepancy by changing the pattern for

147 Meiolania platyceps than by revising all descriptions that followed the incorrect translation of D

148 vs. H scute identification. Thus, we establish the following comparative criteria to identify the D

149 and $\mathrm{H}$ scutes in turtles: the $\mathrm{D}$ scute is in contact with the F-scute series, is positioned

150 anterolaterally to scute $\mathrm{H}$, and commonly extends across parts of the parietal-postorbital suture.

151 The $\mathrm{H}$ scute does not contact the F-scute series, is positioned posteromedially to scute D,

152 contacts the posterior midline scutes (A, and usually but not universally $\mathrm{X}$ ), and does not extend

153 anteriorly onto the postorbital. These criteria allow consistent D vs. H scute identification among

154 the taxa shown by Sterli \& de la Fuente (2013; their fig. 10) and following authors (Fig. 3). In

155 the future, the $\mathrm{H}$ and D scutes of previous Meiolania platyceps illustrations (Gaffney 1983: their

156 fig. 23; Sterli \& de la Fuente, 2013: their fig. 10; Sterli 2015: their fig. 1) should be read in

157 reverse, as shown here in figure 3. Besides the aforementioned change for Meiolania platyceps,

158 our scute identification for Annemys levensis (Fig. 3) deviates slightly from the original one 
159 presented by Rabi et al. (2014: their fig. 1K), and we add the identification of an $\mathrm{H}$ scute to 160 Ordosemys leios (Li et al., 2019).

161 Because not all scute sulci show clearly on USNM 497740, the following reconstruction for

162 Arundelemys dardeni should be seen as tentative (Figs 2-3). None the less, the scute pattern and

163 scute homology across clades is something that may be rewarding in terms of future

164 phylogenetic assessments, and we hope that the following instigates more in-depth research on 165 turtle cranial scutes.

166 The skull of Arundelemys dardeni is covered, for the most part, by relatively large scutes, 167 which is more similar to the pattern seen in derived meiolaniids (e.g. Gaffney, 1983; Sterli, 168 2015) than the pattern of early testudinatans (e.g. Gaffney, 1990; Sterli \& Joyce, 2007). A single, 169 large scute covered the anterior part of the skull anterior to the level of the orbits (Fig. 2B, D), 170 which corresponds to scute $Z$ in the homology concept of Sterli et al. (2013). Immediately

171 posterior, there seems to be another large unpaired scute (scute $\mathrm{Y}$ ) that covers the anterior frontal 172 and prefrontal region (Fig. 2B, D). The skull midline posterior to scute $\mathrm{Y}$ seems to covered by 173 three consecutive scutes. There are no sagittal median sulci that would suggest that any of these 174 midline scutes were paired, but the absence of such sulci cannot be considered strong evidence 175 for their absence, given the discontinuous scute sulcus pattern in the specimen. The first of these 176 three scutes, tentatively identified as scute G, is restricted to the frontals, and, if indeed unpaired, 177 much broader than long (Fig. 2B). In other turtles for which the scute patterns have been 178 reported, scute G is usually paired across the midline (Gaffney, 1983, 1990; Sterli \& de la 179 Fuente, 2013). The posteriorly following scute in USNM 497740 (scute X) is somewhat larger 180 than scute $\mathrm{G}$, but still broader than long, covering the posterior aspect of the frontals and most of 181 the preserved parietal region (Fig. 2B). This scute usually indeed is unpaired, but it is usually 
182 restricted to the parietals (i.e. it does not extend anteriorly onto the frontals) and is often smaller

183 than reconstructed here for Arundelemys dardeni (Sterli \& de la Fuente, 2013). The last

184 preserved median scute of USNM 497740 (scute A), is restricted to the posterior interparietal

185 region (Fig. 2B), and posteriorly incomplete due to breakage in the skull roof. Its anterior,

186 preserved morphology corresponds well with that reported for Mongolochelys efremovi

187 (Khosatzky, 1997; Sukhanov, 2000).

188 The scutes in the temporal region around the postorbital are relatively well defined on the left 189 side of USNM 497740. The posterior part of the prefrontals and the lateral frontal process that 190 extends into the orbit is covered by a relatively small scute (scute $\mathrm{F}_{1}$; Fig. 2B, D). The left and 191 right scutes $F_{1}$ are separated by scute $Y$. Posterior to scute $F_{1}$, there is a pentagonal scute that 192 covers the posterolateral frontal process and the anterior postorbital region, and extends into the 193 orbital margin. We identify this scute as a second $\mathrm{F}$ scute $\left(\mathrm{F}_{2}\right)$, as circumorbital scutes in this 194 region of the orbit are limited to scute F in the concept of Sterli and de la Fuente (2013), which 195 in non-meiolaniid taxa is generally developed as a series of scutes. Topological arguments with 196 respect to anteriorly and laterally adjacent scutes support this identification: the respective scute 197 of USNM 497740 has (i) an anterior contact with scute $\mathrm{F}_{1}$; (ii) an anteromedial contact with 198 scute G; and (iii) a lateral contact with scute G. Our interpretation results in the observation that the $\mathrm{F}_{2}$ scute of Arundelemys dardeni has an additional, medial contact with scute $\mathrm{X}$, which also 200 prevents a contact between scutes $G$ and D. This is not seen in other turtles for which the scute

201 patterns have been reported (Sterli \& de la Fuente, 2013; Rabi et al., 2013, 2014; Sterli, 2015; Li 202 et al., 2019). However, this can be explained by the large size of the X scute in Arundelemys 203 dardeni, which can be identified with high certainty, and which is much larger than in other 204 turtles (Sterli \& de la Fuente, 2013; Rabi et al., 2014). Additional, tentative evidence for our 
205 identification comes from the baenid Neurankylus torrejonensis (Lyson et al., 2016). Although

206 scute identities are tricky for this taxon, as there seems to be a partial reduction of midline scutes,

207 the scute that covers the postorbital parietal region posterior to the circumorbital scutes can be

208 identifies as a D scute, and it also lacks a contact with the anterior midline scutes. Thus, the

209 absence of a d-G scute contact may be common feature of paracryptodires. Posterior to our scute

$210 \mathrm{~F}_{2}$, there is a moderately sized scute in Arundelemys dardeni that covers the parietal and

211 postorbital suture, which we identify as scute D (Fig. 2B, D), following the arguments laid out

212 for D scute identification above. Between scutes D and A, there is a scute that as preserved is

213 restricted to the parietals of USNM 497740 (Fig. 2B), and which can be tentatively identified as

214 scute $\mathrm{H}$, again following above arguments.

215 The lateral surface of the skull also shows scute sulci. The orbito-temporal region is dorsally

216 covered by a large scute tentatively identified as scute $\mathrm{F}_{3}$ based on its dorsal contact with scutes

$217 \mathrm{~F}_{2}$ and $\mathrm{D}$, its contact with the orbital margin, and its position that is restricted to the postorbital

218 (see Sterli \& de la Fuente, 2013). Ventral to scute $F_{3}$, USNM 497740 has two scutes between the

219 orbit and cheek emargination (Fig. 2D). Both are herein attributed to the $\mathrm{J}$-series. $\mathrm{J}_{1}$ is a small

220 scute in the orbital margin, which covers the postorbital-maxilla contact (Fig. 2D). Posteriorly

221 adjacent is the larger $\mathrm{J}_{2}$, which completely covers the jugal and its sutures with the postorbital

222 and maxilla (Fig. 2D). Along the maxilla, no sulci can be inferred except those defining the J-

223 series as well as the one defining scute $\mathrm{Z}$ ventrally. Thus, it seems that the maxilla and

224 premaxilla were covered by a single large scute I (Fig. 2D).

225

226 Nasal. Both nasals of USNM 497740 are preserved (Fig. 1A,F). The nasal of Arundelemys

227 dardeni has a relatively large dorsal exposure. It contacts the frontal posteriorly, the prefrontal 
228 posterolaterally, and the maxilla laterally. Medially, there is a short inter-nasal contact that is

229 posteriorly prohibited by the anterior processes of the frontals (Fig. 1A). The nasal is

230 horizontally aligned with the plane of the frontal, and does not slope anteroventrally like in

231 Uluops uluops (Rollot, Evers \& Joyce, in press) or Pleurosternon bullockii (Evans \& Kemp,

232 1975; Evers, Rollot \& Joyce, 2020). Instead, the anterior margin of the nasal, which forms the

233 dorsal margin of the external naris, is anteriorly oriented, contributing to a high snout region

234 similar to that of Trinitichelys hiatti (Gaffney, 1972). On their ventral surface, there is a broad,

235 transverse ridge crossing both nasals (Fig. 4A), which is absent in Uluops uluops.

236

237 Prefrontal. Both prefrontals are preserved in USNM 497740 (Fig. 1A,C-D). The prefrontal of

238 Arundelemys dardeni contacts the frontal medially, the nasal anteriorly, the maxilla

239 anterolaterally, the vomer ventromedially, and the palatine posteroventromedially. As described

240 by Lipka et al. (2006), the prefrontal has a rectangular exposure on the skull roof (Fig. 1A).

241 However, this prefrontal exposure is reduced with regard to most turtles, similar to the condition

242 of Uluops uluops (Rollot, Evers \& Joyce, in press) and Pleurosternon bullockii (Evers, Rollot \&

243 Joyce, 2020), but not as strongly as in baenodds (e.g., Gaffney, 1972; Lyson \& Joyce, 2009a, b;

244 Rollot, Lyson \& Joyce, 2018; Lyson, Sayler \& Joyce, 2019). Left and right elements are

245 separated by broad anterior frontal processes. The ventral process of the prefrontal is transversely

246 broad and frames a narrow fissura ethmoidalis. The process has a clear contact with the palatine,

247 which could not be ascertained by Lipka et al. (2006). The prefrontal forms the dorsal border of

248 a larger foramen orbito-nasale, which is otherwise framed by the maxilla and the palatine. An

249 unusual feature of the prefrontal of Arundelemys dardeni is a medially projecting sheet-like ridge

250 on the medial surface that faces the inside of the nasal cavity (Fig. 4A). This ridge is absent in 
251 Uluops uluops (Rollot, Evers \& Joyce, in press) or Pleurosternon bullockii (Evers, Rollot \&

252 Joyce, 2020).

253

254 Frontal. Both frontals are well preserved in USNM 497740 (Fig. 1A,C-D,F). The frontal of

255 Arundelemys dardeni is distinct in its shape. The anterior process of the frontal, which extends

256 medial to the prefrontal and contacts the nasal anteriorly, is very broad, similar to the condition

257 in Uluops uluops (Rollot, Evers \& Joyce, in press), but different from the particularly narrow

258 processes seen in Pleurosternon bullockii (Evans \& Kemp, 1975; Evers, Rollot \& Joyce, 2020).

259 The process is parallel with its lateral margin to the sagittal plane for the length of the prefrontal,

260 but anteriorly tapers toward the midline, forming with its counterpart a distinct "V"-shaped

261 projection that separates the nasals (Fig. 1A). The anterior frontal process extends dorsally to

262 roof the nasal cavity and extends the sulcus olfactorius into the nasal cavity (Fig. 4A). The

263 cristae cranii on the ventral surface, which define the sulcus olfactorius are distinct ridges (Fig.

264 4A), but become shallow posteriorly so that they are not confluent with the anteroventral margin

265 of the descending process of the parietal. The frontal has a short lateral process that contributes

266 to the orbital margin between the prefrontal and postorbital (Fig. 1A,C-D), as noted by Lipka et

267 al. (2006). Posterolaterally, the frontal extends between the parietal and postorbital, forming a

268 broad pointed process (Fig. 1A). Consequently, the suture with the parietal is not approximately

269 mediolaterally oriented, as in Pleurosternon bullockii (Evers, Rollot \& Joyce, 2020) and Uluops

270 uluops (Rollot, Evers \& Joyce, in press), but instead crosses the skull roof obliquely from the

271 contact with the postorbital anteromedially, as in baenodds such as Baena arenosa, Chisternon

272 undatum, Eubaena cephalica, Palatobaena cohen, or Saxochelys gilberti (Gaffney 1972; Lyson

273 and Joyce, 2009a; Rollot, Lyson \& Joyce, 2018; Lyson, Sayler \& Joyce, 2019). 
275 Parietal. Both parietals are incompletely preserved in USNM 497740 (Fig. 1A,C-F). This

276 assessment is in contrast to what was reported by Lipka et al. (2006), who interpreted the

277 parietals to be unbroken in the parietal-postorbital region and extremely deep dorsal skull

278 emarginations to be present. Lipka et al. (2006) cite two primary reasons for their interpretation,

279 in particular the absence of trabecular intersections along the margins of the purported upper

280 temporal emargination and the thinning of the bones towards the margins. In our reassessment of

281 CT scans, we find numerous trabecular intersections along the parietal margins, contra Lipka et

282 al. (2006). In addition, the thinning of the parietal toward its margin observed by Lipka et al.

283 (2006) is irregular and not symmetrical for both skull sides (Figs 1E, 4B). These observations,

284 therefore, indicate that the preserved parietal margin is the result of breakage. Comparative

285 anatomical reasons support the hypothesis that the temporal roof is damaged. In all

286 paracryptodires from which this region is known, the parietals form an expanded posteromedian

287 process that overlaps the supraoccipital almost completely, even in taxa with moderately deep

288 emarginations (e.g. Pleurosternon bullockii: Evans \& Kemp, 1975; Evers, Rollot \& Joyce, 2020)

289 or deep emarginations (e.g. Plesiobaena antiqua: Brinkman, 2003, Palatobaena cohen: Lyson \&

290 Joyce, 2009a). As preserved, this process is absent in Arundelemys dardeni. Additionally, in all

291 known paracryptodires, including palatobaenins with comparatively deep emarginations (Joyce

292 \& Lyson, 2015), the posterior and posterolateral parietal margin prohibits most of the prootics to

293 be seen in dorsal view. Arundelemys dardeni would be the only paracryptodire, in which the

294 prootics are completely exposed in dorsal view (Fig. 1A). Finally, significant damage is apparent

295 to the supraoccipital and quadrates as well (see below). Thus, the combined observations

296 presented here suggest that both the postorbitals, parietals, and jugals are missing their posterior 
297 portions, making it impossible to assess the depth of dorsal emarginations in Arundelemys 298 dardeni.

299 The preserved parts of the parietal show contacts with the frontal anteriorly, the postorbital 300 anterolaterally, the other parietal across the skull midline, the supraoccipital posteroventrally, the 301 prootic posteroventrolaterally, the epipterygoid ventrally along the descending process, and a 302 possible but short contact with the crista pterygoidei of the pterygoid medially to the 303 epipterygoid (Fig. 1A,C-F). The skull roof as formed by the parietals slopes upwards 304 posteriorly. Ventrally, the parietal forms a descending process, which overlaps the anterolateral 305 surface of the supraoccipital posteriorly, articulates tightly with the prootic, forms the dorsal 306 margin of the trigeminal foramen posterior to its contact with the epipterygoid, and forms the 307 anterior margin of braincase, which also functions as the posterior margin of the foramen 308 interorbitale (Fig. 1C-D). It is unclear if the parietal would have excluded the prootic from the 309 trigeminal foramen via a posteroventral process, as in in Pleurosternon moncayensis (Pérez310 García et al., 2021). As recently reported for Pleurosternon bullockii (Evers, Rollot \& Joyce, 311 2020), the lateral surface of the descending parietal process bears a strong lateral ridge (Fig. 4B),

312 which contacts the postorbital and defines the dorsal aspects of a septum orbito-temporale with

313 it, similar to the condition seen in pleurodires. Thus, orbital and temporal fossae are clearly 314 delimited in Arundelemys dardeni.

315

316 Postorbital. Both postorbitals are incompletely preserved in USNM 497740 (Fig. 1) and the

317 reader is referred to the parietal section above for arguments as to why we think that significant

318 portions of the postorbital are broken off posteriorly. What remains of the postorbital laterally

319 contacts the frontal and parietal in the skull roof(Fig. 1A). A quadratojugal contact is not 
320 preserved but was likely present, but a possible contact with the squamosal cannot be assessed.

321 Ventrally, the postorbital contacts the maxilla, jugal, and pterygoid along a medially expanded

322 ventral process (Fig. 1C-D). The medial surface of this process is formed as a septum

323 orbitotemporale, a strong ridge separating the orbital and temporal cavities (Fig. 4B). This is

324 similar to pleurodires and Pleurosternon bullockii (Evers, Rollot \& Joyce, 2020), but in

325 Arundelemys dardeni, this wall of bone is even more extensive than in Pleurosternon bullockii.

326 Though not described under that name, a well-developed septum orbitotemporale is also

327 apparent among baenodds such as Eubaena cephalica (Rollot, Lyson \& Joyce, 2018).

328 Ventromedially, the septum orbitotemporale extends all the way to the transverse process of the

329 pterygoid. This is only preserved on the right side of the specimen, but very clearly visible in the

$3303 \mathrm{D}$ models. The ventral postorbital process also forms the majority of the posterior margin of the

331 orbit (Fig. 1C-D), where it has a direct contact with the maxilla, excluding the jugal from the

332 orbital margin.

333

334 Jugal. Both jugals are preserved in USNM 497740 (Fig. 1C-D). The posterior margin of both

335 jugals appears partly broken, so that a possible contact with the quadratojugal cannot be

336 assessed. However, a short piece of the posteroventral margin of the jugal seems to be intact on

337 either side of the skull. This part of the lateral plate of the jugal nearly reaches the labial margin

338 of the maxilla. Instead of being parts of the labial margin sensu stricto, the jugal in this region

339 forms a posterodorsally sloping continuation of the labial margin (Fig. 1C-D). This sloping edge

340 usually forms the anterior margin of the cheek emargination in all paracryptodires but

341 compsemydids (Lyson \& Joyce, 2011), and the sloping edge may thus be seen as tentative

342 evidence that the cheek emargination was similarly moderately deep as in baenids (Joyce \& 
343 Lyson, 2015) and pleurosternids (Evers, Rollot \& Joyce, 2020). Although the jugal of

344 Arundelemys dardeni is thus positioned somewhat dorsally to the ventral skull margin as formed

345 by the labial margin of the maxilla, the ventral extend of the jugal is deeper than in

346 Pleurosternon bullockii (Evers, Rollot \& Joyce, 2020), Uluops uluops (Rollot, Evers \& Joyce, in

347 press), and instead more similar to the condition seen in Palatobaena cohen (Lyson \& Joyce,

348 2009a) or Plesiobaena antiqua (Brinkman, 2003), although this is not the universal condition in

349 baenids (e.g., Trinitichelys hiatti: Gaffney, 1972; Eubaena cephalica: Rollot, Lyson \& Joyce,

350 2018). As already observed by Lipka et al. (2006), the jugal is very clearly excluded from

351 contributing to the orbital margin by a postorbital maxilla contact (Fig. 1B-C). Nonetheless, the

352 jugal is broadly exposed in the posterior floor of the orbital fossa (Fig. 4A). Here, it forms the

353 ventral extension of the septum orbitotemporale (Fig. 4B). Like the postorbital, the jugal has a

354 clear medial contact with the pterygoid (Fig. 4B). In fact, the jugal posteromedially even extends

355 slightly onto the transverse process of the pterygoid, or more specifically, its horizontally

356 exposed lateral flange.

357

358 Quadratojugal. Both quadratojugals are not preserved in USNM 497740 and the quadrates are

359 too incompletely preserved to infer their presence based on respective articulation facets. Given

360 that other paracryptodires have quadratojugals, their absence in Arundelemys dardeni most likely

361 is a preservational artefact.

362

363 Squamosal. Both squamosals are not preserved in USNM 497740. 
365 Premaxilla. Both premaxillae are completely preserved in USNM 497740 (Fig. 1B-D, F). The

366 premaxilla forms the anteroventral tip of the snout, and contacts the maxilla laterally, and the

367 vomer posteriorly, and its counterpart medially. Several features of the premaxilla of

368 Arundelemys dardeni are noteworthy. The bone is anteroposteriorly elongate, contributing to an

369 extensive ventral exposure (Fig. 1B). The premaxilla is relatively broad and completely

370 surrounds the foramen praepalatinum (Fig. 1B), a feature also seen in Pleurosternon bullockii

371 (Evers, Rollot \& Joyce, 2020) and some baenodds (Gaffney, 1972). This condition differs

372 strongly from the premaxilla described for Compsemys victa (Lyson \& Joyce, 2011), which is

373 transversely narrow in ventral view. USNM 41614 also differs in the triturating surface ridges

374 from Compsemys victa: The labial ridge of USNM 497740 is low and even and continuous with

375 the maxilla, as the vast majority of paracryptodires. A ventrally recurved hook, as developed in

376 Compsemys victa (Lyson and Joyce, 2011), is absent. A lingual ridge is very clearly developed.

377 It is discontinuous at the median interpremaxillar contact (Fig. 1B), but becomes deeper

378 posterolaterally toward the maxilla, where the ridge becomes extremely prominent and deeper

379 than the labial ridge (Fig. 1F). The lingual ridges define a median depression in the triturating

380 surface formed by the premaxilla, maxilla, and vomer, that is commonly referred to as the

381 "tongue groove" and found in numerous baenodds, including Baena arenosa (Gaffney 1972),

382 Eubaena cephalica (Rollot, Lyson \& Joyce, 2018), "Plesiobaena" antiqua (Brinkman, 2003).

383

384 Maxilla. Both maxillae of USNM 497740 are well preserved (Fig. 1B-D, F). The bone has a 385 posterior process that extends ventral to the orbit to contact the postorbital, jugal, and pterygoid.

386 Along its medial margin, the maxilla broadly contacts the palatine, and, anterior to the foramen

387 orbito-nasale, the vomer and the premaxilla (Fig. 1B). Along its ascending process, which 
388 frames the orbit anteriorly, the maxilla contacts the nasal, and, posterior to this contact, the 389 prefrontal (Fig. 1C-D).

390 The medial surface of the ascending process of the maxilla is dominated by a medially 391 projected ridge, which abuts the prefrontal. Ventrally, the ridge very clearly defines the nasal 392 ducts that connect the nasal cavity with the internal naris (Fig. 4A). The ridge slopes ventrally 393 lower within the orbital cavity, where it forms the floor of the latter, contributes to the foramen 394 orbito-nasale, and extends posteriorly to the pterygoid.

395 As in many paracryptodires, the ventral margin of the maxilla forms a slightly convex labial 396 ridge (Fig. 1C-D). The labial ridge is deep posteriorly, but becomes slightly shallower 397 anteriorly. Over the entire extent of the maxilla, the triturating surface is deeply grooved between 398 the labial ridge laterally and the lingual ridge medially (Figs 1B, 4A). Lipka et al. (2006) noted 399 relatively large openings in the triturating surface of the maxilla, which they interpreted, after 400 also considering breakage, as "architectural features reflecting the distribution of stresses through 401 the triturating surface" (Lipka et al., 2006: p. 304). We here interpret these openings as a result 402 of erosion (Fig. 1B). As already noted by Lipka et al. (2006), the CT scan shows that the 403 maxillary bone is thin in this region, and this seems to be safely attributable to abrasion.

404 Additionally, the openings are only superficially bilaterally symmetrical (Fig. 1B), arguing 405 against being part of the natural morphology of Arundelemys dardeni. As a final argument, it is 406 biomechanically hard to conceive how holes in the surfaces for food processing should mitigate 407 stresses from processing food on these very surfaces: Finite element analysis of turtle skulls 408 which simulate biting behaviour show that the triturating surfaces between labial and lingual 409 ridges are the least stressed skull snout regions during biting, and that high stresses are actually 410 concentrated along palatal openings, including the foramen prepalatinum, foramen palatinum 
411 posterius, or internal naris (Ferreira et al., 2020). The lingual ridge of USNM 497740 is very

412 strongly developed (Lipka et al., 2006; Figs 1B, F, 2A), which is unlike the condition in

413 Pleurosternon bullockii (Evans \& Kemp, 1975; Evers, Rollot \& Joyce, 2020) or Uluops uluops

414 (Rollot, Evers \& Joyce, in press). The lingual ridge of USNM 497740 becomes deeper anteriorly

415 and is most prominent at the level of the articulation with the vomer. The better development of

416 the lingual ridge in the anterior half of the palate is a feature commonly found among baenodds,

417 including Baena arenosa (Gaffney, 1972), Plesiobaena antiqua (Brinkman, 2003), or

418 Stygiochelys hiatti (Gaffney, 1972). Medial to the labial ridge, the maxilla slopes dorsally toward

419 the vomer in this region, which results in a morphology in which the vomer-premaxilla contact

420 seems deeply embedded between the lingual ridges in ventral view, the aforementioned "tongue

421 groove" (see Premaxilla above) typical of baenodds (Fig. 1B).

422 Posteromedially, the maxilla contacts the palatine (Fig. 1B). Posterior to this contact, the

423 maxilla has a short contribution to the foramen palatinum posterius, before the maxilla contacts

424 the anterolateral portion of the transverse process of the pterygoid.

425

426 Vomer. The vomer is a singular, median bone with only minor damage in USNM 497740 (Fig.

427 1B). The vomer forms a broad anteroventral surface between the articulation with the right and

428 left maxillae to form a "tongue groove" (see Premaxilla above). This surface anteriorly contacts

429 the premaxillae, with which it forms a short triturating surface between the maxillary lingual

430 ridges (Fig. 1B). Posteriorly, the vomer extends from this surface as a posteriorly narrowing

431 process that is wedged between the palatines and that contacts the pterygoids with its posterior

432 tip (Fig. 1B). The ventral surface of the vomer is without a medial keel. A sulcus vomeri is 
433 formed on the dorsal surface of the vomer between the anterolateral processes that contact the

434 prefrontals.

435

436 Palatine. Only the right palatine is preserved in USNM 497740 (Fig. 1B). The palatine is a flat

437 element that is centrally constricted between its anteroposteriorly broadened medial and lateral

438 margins. The lateral margin contacts the maxilla and minorly contributes to the lingual ridge

439 (Lipka et al., 2006), which posteriorly becomes broad and low (Fig. 1B). Medially, the palatine

440 lies against the vomer anteriorly and the pterygoid posteriorly, so that a median interpalatine

441 contact is absent (Lipka et al., 2006). A short anterior contact with the prefrontal is also present.

442 The foramen palatinum posterius is anteriorly framed by the palatine (Fig. 1B) and the concave

443 anterior margin of the bone defines the posterior margin of the internal naris.

444

445 Quadrate. Both quadrates of USNM 497740 are incompletely preserved (Fig. 1BA-E). In

446 addition, the sutures with the prootic and opisthotic are very tight and only distinct in places in

447 the CT scan, resulting in some sutural approximation in our segmentations, particularly with the

448 opisthotic (note stippled sutural lines in Fig. 2). Besides contacts with these two bones, the

449 quadrate preserves a contact with the pterygoid. Contacts with the quadratojugal and squamosal

450 were near certainly present, but this cannot be confirmed due to the absence of these bones or the 451 appropriate sutures.

452 The preserved parts of the quadrate of USNM 497740, particularly on the left side, show that

453 the incisura columella auris was a widely open posteriorly (Figs 1C, 4B), which is distinct from

454 the narrow slits of Dorsetochelys typocardium (Evans \& Kemp, 1976), Pleurosternon bullockii

455 (Evans \& Kemp, 1975; Evers, Rollot \& Joyce, 2020), Pleurosternon moncayensis (Pérez-García 
456 et al., 2021), Uluops uluops (Rollot, Evers \& Joyce, in press) or baenids (Gaffney, 1972). It is

457 also distinct from the morphology of Compsemys victa, in which the incisura becomes

458 posterolaterally enclosed by a contact between a posterodorsal process of the quadrate and a

459 posteroventral process of the squamosal (Lyson \& Joyce, 2011). Although the latter is not

460 preserved in USNM 497740, the posterior surface of the left quadrate is well-preserved and lacks

461 features that would indicate that a posterodorsal quadrate process is broken or that the squamosal

462 would have extended far ventrally to contact the quadrate. The stapedial canal is formed between

463 the quadrate and prootic on both sides, but its dorsal aperture, the foramen stapedio-temporale,

464 has an additional contribution of the opisthotic on the left side (absent on right side), showing

465 polymorphism in this feature (Fig. 1B). The anterior quadrate contact with the pterygoid is clear

466 in the CT scans and they show than an anteriorly directed epipterygoid process is absent in

467 Arundelemys dardeni (Fig. 1C).

468

469 Epipterygoid. Both epipterygoids are well preserved in USNM 497740 (Fig. 1C-D, 4B) and

470 clearly visible in the CT slices. However, our interpretation of the epipterygoid position and

471 shape differs strongly form that of Lipka et al. (2006). These authors figure the epipterygoid as a

472 rod-like element (their fig. $2 \mathrm{H}$ ), which forms the ventral margin of the trigeminal foramen with

473 its dorsal margin and extends posteroventrally to the quadrate from there. However, this

474 configuration would be highly unusual, as the epipterygoid of turtles usually ossifies between the

475 crista pterygoidei of the pterygoid and the descending process of the parietal anterior to the

476 trigeminal foramen, and not posterior to it (Gaffney, 1979). In addition, an epipterygoid-quadrate

477 contact is only present in turtles when an anteriorly directed, thin epipterygoid process of the

478 quadrate is present (Gaffney, 1979), which is not the case in Arundelemys dardeni. The CT scans 
479 of USNM 497740 instead show a more usual epipterygoid shape and position for Arundelemys

480 dardeni: the epipterygoid is ossified between the descending process of the parietal and the crista

481 pterygoidei of the pterygoid, prohibiting a broad contact between these bones (Figs 1C-D, 4B).

482 It forms the anteroventral margin of the trigeminal foramen and contacts the pterygoid

483 posteriorly, but not the quadrate. An unusual feature of the epipterygoid of Arundelemys dardeni

484 is a large opening along its ventral contact with the pterygoid (Figs 1C-D, 4B). This opening is

485 symmetrically present on both sides of the skull and the CT scans do not indicate any damage in

486 this region, from which we gather that the opening may represent a true foramen. The foramen

487 forms a connection between the sulcus cavernosus and the temporal fossa. We are only aware of

488 a similar opening in the Cretaceous sandownid turtle Sandownia harrisi (Evers \& Joyce, 2020),

489 in which the respective foramen was interpreted as a potential foramen for the mandibular artery,

490 which, in many turtles, extends through the canalis cavernosus alongside the lateral head vein

491 until it exits either through a separate foramen posterior to the trigeminal foramen, or through the

492 trigeminal foramen itself (see Rollot, Evers \& Joyce, 2021b).

493

494 Pterygoid. The left pterygoid of USNM 497740 is completely preserved (Fig. 1B), whereas the

495 right element is abraded posteriorly. As in all turtles, the pterygoid morphology is complex with

496 many processes contributing to different structures. Anteriorly, the pterygoid of Arundelemys

497 dardeni has a conspicuous anteromedial process, which medially contacts the other pterygoid

498 forming a long anterior spur that contacts the vomer and which separates the palatines along the

499 skull midline (Figs 1B, 5A). Such processes are present in other early paracryptodires, for

500 example Uluops uluops (Rollot, Evers \& Joyce, in press). Posterior to the level of the processes,

501 but still along the anterior part of the bone, the pterygoid of USNM 497740 has a laterally 
502 directed transverse process, which contacts the maxilla, jugal and postorbital (Fig. 1B, 4B). The

503 lateral surface of the transverse process is expanded to the typical vertical flange, but the tip of

504 the process, in general, is much smaller than in Uluops uluops (Rollot, Evers \& Joyce, in press)

505 or Pleurosternon bullockii (Evers, Rollot \& Joyce, 2020). However, similar to these taxa, the

506 vertical flange of the transverse process is slightly medially recurved along its dorsal margin,

507 establishing a slight reminiscence of the pleurodire condition of this process.

508 The interpterygoid contact of USNM 497740 is long (Lipka et al., 2016), but right and left

509 pterygoids diverge mid-length to make room for the median parabasisphenoid, and, more

510 posteriorly, the basioccipital (Fig. 1B, 4B). The posterior process of the pterygoid is very

511 extensive in Arundelemys dardeni, extending over the full length of parabasisphenoid and

512 basioccipital, also contacting the exoccipital (Fig. 1E). This is different from the condition in

513 Uluops uluops, in which the pterygoid only extends to the level of the basioccipital (Rollot,

514 Evers \& Joyce, in press), but similar to the condition of baenodds (e.g. Rollot, Lyson \& Joyce,

515 2018). The posterior pterygoid process of USNM 497740 fully covers the cavum acustico-

516 jugulare in ventral view, and has a notably deep pterygoid fossa between quadrate and

517 parabasisphenoid (Lipka et al., 2006; Fig. 1B). Along the suture with the parabasisphenoid, the

518 pterygoid contributes to a carotid pit (see parabasisphenoid; Fig. 5). Just posterior to the carotid

519 pit, there is a small foramen distalis nervi vidiani and associated canalis pro ramo nervi vidiani

520 (sensu Rollot, Lyson \& Joyce, 2018; Fig. 5A-B) for the posterior course of the vidian nerve.

521 This canal traverses the pterygoid dorsoventrally, and connects the canalis cavernosus with the

522 ventral skull surface. In Uluops uluops (Rollot, Evers \& Joyce, in press) and Pleurosternon

523 bullockii (Evers, Rollot \& Joyce, 2020) there is a small foramen posterius canalis nervi vidiani

524 (sensu Rollot, Lyson \& Joyce, 2018) in the anterior region of the carotid pit through which the 
525 vidian nerve enters the pterygoid to extend through a long canal traversing the bone. In USNM

526 41616, such a foramen is also apparent within the carotid pit (Fig. 5B), albeit hard to see in the

527 CT scans. The associated canalis nervus vidianus is also hard to trace through the CT scans,

528 particularly on the right side, but we were able to segment the canal for nearly its full length on

529 both sides. The anterior opening foramen (foramen anterius canalis nervi vidiani) is located on

530 the dorsal pterygoid surface anterior to the base of the crista pterygoidei and close to the position

531 of the foramen palatinum posterius (Fig. 5C).

532 The dorsal surface of the posterior pterygoid process is exposed in the floor of the cavum

533 acustico-jugulare, where it forms a broad anteroposteriorly directed groove for the course of the

534 lateral head vein. Together with the prootic, the pterygoid forms the canalis cavernosus for the

535 anterior course of the lateral head vein. At the level of the anterior end of the canalis cavernosus,

536 the pterygoid has a dorsally raised crista pterygoidei, which forms the ventral margin of the

537 trigeminal foramen (Figs $\mathbf{1 C}-\mathbf{D}, \mathbf{4 B}, \mathbf{5 C})$. Anterior to the trigeminal foramen, the pterygoid

538 broadly contacts the epipterygoid, and forms the ventral border of the possible mandibular artery

539 foramen (see epipterygoid) that opens in the lateral wall of the braincase between both bones

540 (Figs 1C-D, 4B). Medial to the crista pterygoidei, the dorsal pterygoid surface bears a distinct

541 sulcus cavernosus (Fig. 5C). The anterior abducens nerve foramina are positioned in the suture

542 between pterygoid and parabasisphenoid (Fig. 5C), as is also the case in Pleurosternon bullockii

543 (not stated in Evers, Rollot \& Joyce, 2020, but apparent from their models). In Uluops uluops,

544 these foramina even lie entirely within the pterygoid (Rollot, Evers \& Joyce, in press). This

545 lateral placement of the anterior abducens nerve foramina in the aforementioned taxa is highly

546 unusual, as these foramina are usually positioned in the parabasisphenoid in all other known 
547 turtles (Gaffney, 1979; Rollot, Evers \& Joyce, in press). Their position has not yet been clarified

548 in baenodds.

549

550 Supraoccipital. The supraoccipital is incompletely preserved in USNM 497740 (Fig. 1A, C-E),

551 missing nearly its entire crest. This differs from the interpretation of Lipka et al. (2006), whose

552 descriptions suggest the supraoccipital were basically complete. For example, Lipka et al. (2006)

553 state that Arundelemys dardeni has a short but sharp-edged supraoccipital crest that slopes from

554 the parietals to the foramen magnum. However, this entire dorsal edge is broken (Fig. 1C-D)

555 and a broad triangular break above the foramen magnum indicates that a relatively large piece of

556 the bone is missing in this area. As such, it is impossible to assess the length of the supraoccipital

557 crest. As already discussed in the parietal section, the dorsal edge of the supraoccipital as

558 preserved would have been overlain by posterior parietal processes, as in other paracryptodires,

559 preventing the current complete dorsal exposure of the bone (Fig. 1A).

560 The ventral part of the supraoccipital of USNM 497740 is expanded over the braincase to

561 form its roof, and contacts, from posterior to anterior, the exoccipital, opisthotic, prootic, and

562 parietal (Fig. 1A,E).

563

564 Exoccipital. Both exoccipitals of USNM 497740 are preserved (Fig. 1E), but the morphology of

565 this bone was not described in the original description (Lipka et al., 2006). The exoccipital forms

566 the lateral margin of the foramen magnum, but right and left elements neither meet in the dorsal,

567 nor in its ventral margin (Fig. 1E). As in Uluops uluops (Rollot, Evers \& Joyce, in press) or

568 Pleurosternon moncayensis (Pérez-García et al., 2021), the exoccipitals do not seem to

569 contribute to the occipital condyle - although the condyle is abraded in the specimen, the 
570 posterior processes of the exoccipitals end shortly posterior to the level of the foramen magnum,

571 but this could be the result of damage as well. The ventral footplate of the exoccipital that abuts

572 the basioccipital is relatively high and forms a nearly circular foramen jugulare anterius with the

573 opisthotic (Fig. 4B). The exoccipitals of Arundelemys dardeni have a broadly developed contact

574 with the pterygoid.

575

576 Basioccipital. The basioccipital of USNM 497740 is preserved with the exception of the

577 occipital condyle, which appears to be missing (Fig. 1B). It contacts the parabasisphenoid

578 anteriorly, the pterygoid laterally, the exoccipital laterodorsally, and has a small contact with the

579 opisthotic along the area of the hiatus acusticus between the braincase and cavum labyrinthicum.

580 The basioccipital is much broader mediolaterally than it is long anteroposteriorly (Fig. 1B). The

581 ventral surface is gently excavated by a shallow fossa between the basioccipital tuberculae,

582 which are low mounts in the basioccipital-pterygoid contact area. A very low basis tuberculi

583 basalis is developed on the dorsal surface of the basioccipital at the contact with the anteriorly

584 adjacent parabasisphenoid. We can find no evidence of a canalis basioccipitalis, a canal of

585 unclear function found in many baenodds (Rollot, Lyson \& Joyce, 2018).

586

587 Prootic. Both prootics are preserved in USNM 497740 (Fig. 1A,C-D), but the prootic

588 morphology was not described in Lipka et al. (2006). As usual in turtles, the prootic contacts the

589 supraoccipital dorsally, the opisthotic posteriorly, the quadrate laterally, the pterygoid ventrally,

590 the parabasisphenoid medioventrally, and the parietal anterodorsally. The anterodorsal surface of

591 the prootic, which is exposed within the temporal fossa, is transversely concavely flexed to form

592 the anterior half of the poorly developed otic trochlea. Similarly indistinct otic trochlear are also 
593 present in other early paracryptodires, including Pleurosternon bullockii (Evers, Rollot \& Joyce, 594 2020) and Uluops uluops (Rollot, Evers \& Joyce, in press). As preserved, the prootic of 595 Arundelemys dardeni contributes to the trigeminal foramen (Fig. 1C-D). This differs from the 596 condition of Pleurosternon moncayensis (Pérez-García et al., 2021), in which the prootic is 597 excluded from contributing to the foramen by a posteroventral ramus of the parietal. This process 598 may be broken off in Arundelemys dardeni (see left side, Fig. 1C), but may also be genuinely 599 absent.

600 Internally, most of the prootic is excavated for the cavities that constitute the anterior part of 601 the cavum labyrinthicum. Ventrally, the prootic is expanded in the floor of the cavum 602 labyrinthicum and forms much of its floor. The fenestra ovalis is completely surrounded by the 603 prootic and opisthotic, i.e. there is a ventral contact with the processus interfenestralis of the 604 opisthotic, as for instance also in Pleurosternon moncayensis (Pérez-García et al., 2021). The 605 pericapsular recess on the posterior surface of the prootic immediately lateral to the fenestra 606 ovalis (see Evers \& Benson, 2019) is very well developed in Arundelemys dardeni, and both 607 deeper and broader than in Pleurosternon bullockii (Evers, Rollot \& Joyce, 2020) or Uluops 608 uluops (Rollot, Evers \& Joyce, in press). The recess is developed directly dorsal to the posterior 609 entrance foramen of the canalis cavernosus, which is roofed by the prootic. In this dorsal roof, 610 Arundelemys dardeni has a very clearly developed sulcus for the hyomandibular branch of the

611 facial nerve (VII; see Rollot, Evers \& Joyce, 2021b). Other features associated with the facial 612 nerve is the canalis nervus facialis, which extends mediolaterally through the prootic from the 613 fossa acustico-facialis into the canalis cavernous (Fig. 5B-C). This morphology implies that the 614 geniculate ganglion and facial nerve split into vidian and hyomandibular branches was located in 615 the canalis cavernosus (Rollot, Evers \& Joyce, 2021b), which is also corroborated by the 
616 presence of a canalis pro ramo nervi vidiani slightly more anteriorly within the canalis

617 cavernosus and the pterygoid (Fig. 5B). The acoustic nerve has a short canal/foramen from the

618 fossa acustico-facialis directly into the cavum labyrinthicum (Fig. 5C).

619

620 Opisthotic. Both opisthotics of USNM 497740 are partially preserved (Fig. 1A, E), but were not 621 described initially by Lipka et al. (2006). The left opisthotic is more complete than the right one, 622 and shows all of the contacts with other cranial elements: the supraoccipital dorsomedially, the

623 prootic anteriorly, the quadrate laterally, the exoccipital posteroventrally, and the pterygoid

624 ventrally. Additionally, a short contact with the basioccipital is present anterior to the position of

625 the foramen jugulare anterius. The opisthotic forms the posterior portion of the cavum

626 labyrinthicum. It completely forms the lateral semicircular canal (i.e. the prootic portion of the

627 canal remains medially open toward the cavum), and the processus interfenestralis forms a

628 footplate in the floor of the cavum labyrinthicum. The fenestra ovalis is completely embraced by

629 the prootic and opisthotic, and thus ventrally closed. The fenestra perilymphatica is only

630 incompletely preserved on the left side, but opens as usually from the cavum labyrinthicum into

631 the recessus scalae tympani posteriorly. The opisthotic closes the foramen jugulare anterius

632 anteriorly, with the posterior part being formed by the exoccipital (Fig. 4B). The left opisthotic

633 partially preserves foramina for the glossopharyngeal nerve (IX), both an incomplete lateral

634 foramen at the base of the processus interfenestralis, and a medial foramen opening from the

635 braincase into the cavum labyrinthicum are apparent.

636 The paroccipital process is relatively short (Fig. 1E), and the sutures toward the quadrate are

637 not entirely clear due to the tight interdigitation of both bones. This results in slightly odd sutural

638 lines between both models (see dotted sutural lines in Fig. 2). 
639 On the right side, the opisthotic is excluded from contributing to the foramen stapedio-

640 temporale, whereas the bone straddles the aperture for the stapedial canal on the left side (Fig.

641 1A).

642

643 Parabasisphenoid. The parabasisphenoid of USNM 497740 has the usual contacts with the

644 basioccipital posteriorly, the prootic dorsolaterally, and the pterygoid lateroventrally (Fig. 1B).

645 The parabasisphenoid of USNM 497740 has the typical shape seen in non-pleurodiran turtles,

646 being anteroposteriorly longer than mediolaterally wide and acutely triangular, tapering

647 anteriorly between the pterygoids (Fig. 1B). The posterior suture with the basioccipital is straight

648 in USNM 497740, and posterior processes that lap onto the basioccipital and form a secondary

649 pair of basioccipital tubera, features seen in Pleurosternon bullockii, Uluops uluops, and

650 helochelydrids (Joyce et al., 2011; Evers, Rollot \& Joyce, 2020; Rollot, Evers \& Joyce, in press),

651 are absent. Arundelemys dardeni shares with Pleurosternon bullockii and Uluops uluops the

652 presence of a carotid pit in the lateral contact area with the pterygoid (Fig. 5A-B). The carotid

653 pit is similar in position and shape to the fenestra caroticus (sensu Rabi et al., 2013) of some

654 turtles, but differs from it in that there is no posterior bony coverage of the internal carotid artery

655 (Fig. 5B). Like in Pleurosternon bullockii (Evers, Rollot \& Joyce, 2020) and Uluops uluops

656 (Rollot, Evers \& Joyce, in press) the carotid pit is a broadly recessed area around the entry

657 foramen for the cerebral artery. The respective foramen and canal pierce the parabasisphenoid

658 anterolaterally from the carotid pit (Fig. 5A-B). Following recent advances in understanding and

659 changes in nomenclature of the carotid arterial system of turtles (Rollot, Evers \& Joyce, 2021b),

660 we describe the foramen not as a foramen posterius canalis carotici interni (as done by Lipka et

$661 a l ., 2006)$, but as a foramen posterius canalis carotici basisphenoidalis following the ductus of 
662 Rollot et al. (2021b), who did not define this foramen explicitly but re-named osteological

663 structures for the cerebral artery after the bone it traverses, i.e. the parabasisphenoid. Thus, the

664 foramen posterius canalis carotici basisphenoidalis of Rollot et al. (2021b) is equivalent to the

665 foramen posterius canalis carotici cerebralis of Rabi et al. (2013) and the foramen posterius

666 canalis carotici interni of Lipka et al. (2006). Importantly, this particular anatomy suggests that

667 the internal carotid artery of Arundelemys dardeni was completely exposed along the ventral

668 skull surface, that only the cerebral artery enters the canal in the basisphenoid, and that a palatine

669 artery must have either been uncovered in bone, or, more likely, was absent given the absence of

670 a respective canal through the pterygoid-parabasisphenoid region (see pterygoid).

671 Unlike in Pleurosternon bullockii or Uluops uluops, the parabasisphenoid of USNM 497740

672 lacks distinct lateral processes at the level of the carotid pit that could be comfortably labelled as

673 remnant basipterygoid processes. Rather than having such processes inserting laterally into the

674 pterygoid and forming the surface for the carotid pit, as in Pleurosternon bullockii (Evers, Rollot

675 \& Joyce, 2020) and Uluops uluops (Rollot, Evers \& Joyce, in press), the suture between

676 parabasisphenoid and pterygoid of Arundelemys dardeni is dominated by short to medium-length

677 interdigitating bone spurs.

678 Dorsally, the parabasisphenoid of USNM 497740 has roughly parallel lateral margins toward

679 the prootics, and the space between them is deeply transversely concave (Fig. 5C). Posteriorly,

680 there is a low basis tuberculi basalis, which is posteriorly confluent with the crista dorsalis

681 basioccipitalis of the basioccipital. Anteriorly, the parabasisphenoid cup that hold the pons of the

682 hindbrain is finished by a low, step-like dorsum sellae that abruptly slopes vertically into the

683 sella turcica (Fig. 5C). This fossa for the pituitary is only shallowly posteriorly excavated, and

684 holds two foramina anterius canalis carotici basisphenoidalis (sensu Rollot, Evers \& Joyce, 
685 2021b) for the cerebral arteries. Lipka et al. (2006) described the cerebral artery to exit the 686 basisphenoid via a singular foramen, as indeed observed in some turtles (Hooks, 1998; Evers \& 687 Benson, 2019; Evers, Barret \& Benson, 2019; Rollot, Evers \& Joyce, 2021b), but we observe 688 very clearly distinctly separate apertures (Fig. 5C). This misinterpretation probably resulted from 689 examining coronal slices anterior to the true position of the foramina, which would lead to seeing 690 a large cross-sectional area that is the posterior part of the sella turcica itself. To either side of the 691 sella turcica, the parabasisphenoid of USNM 497740 has short and relatively stout anteriorly

692 directed clinoid processes (Fig. 5C). Retractor bulbi pits are present underneath the clinoid 693 process base, but small on either side (Fig. 5C). The anterior abducens nerve foramen lies in the 694 lateral margin of the retractor bulbi pit, at the contact with the pterygoid (Fig. 5C). Although not 695 explicitly stated by Evers et al. (2020), their models of Pleurosternon bullockii show the same 696 morphology, whereas the anterior abducens nerve canal foramina lie even further laterally, 697 completely in the pterygoid in Uluops uluops (Rollot, Evers \& Joyce, in press). This highly 698 unusual feature can probably be used in future phylogenetic or systematic assessments, but its 699 distribution across the tree will need to be established first. Anterior to the sella turcica, the 700 parabasisphenoid of USNM 497740 continues as a flat but relatively broad rostrum

701 basisphenoidale (Fig. 5C), but it terminates a long way before the anterior pterygoid processes, 702 thus not reaching the vomer.

703

704 Stapes. The stapes is not preserved in USNM 497740.

705

706 Labyrinth. Although the labyrinth of USNM 497740 (Fig. 6) conforms to the general labyrinth 707 morphology of turtles of having a roughly pyramidal outline in lateral view with nearly 
708 symmetrical vertical semicircular canals (Georgi \& Sipla, 2008; Walsh et al., 2009; Neenan et

709 al., 2017; Lautenschlager, Ferreira \& Werneburg, 2018; Evers et al., 2019), there are distinct

710 differences with the labyrinth of Uluops uluops (Rollot, Evers \& Joyce, in press), but similarities

711 to the labyrinth of Pleurosternon moncayensis (Pérez-García et al., 2021). A detailed comparison

712 with Pleurosternon moncayensis is complicated by the sheared preservation of the latter. Overall,

713 the vertical semicircular canals of Arundelemys dardeni are more symmetrical than the ones of

714 Uluops uluops, with the anterior semicircular canal being only slightly longer than the posterior

715 one (Fig. 6A). The vertical semicircular canals are also more rounded along their entire extent.

716 The 'M'-shaped embayment at the common crus that was described for Pleurosternon

717 moncayensis (Pérez-García et al., 2021) and which is also present in Uluops uluops is

718 inconspicuous in Arundelemys dardeni (Fig. 6A). The ampulla for the lateral semicircular canal

719 is not distinctly apparent in the 3D model of USNM 497740, whereas it shows as a dorsally

720 expanded area in Uluops uluops (Rollot, Evers \& Joyce, in press). In Arundelemys dardeni, all

721 semicircular canals are relatively slender and have small cross-sectional circumferences (Fig. 6),

722 which is as in Pleurosternon moncayensis (Pérez-García et al., 2021), but contrasts with the

723 relatively thick canals in Uluops uluops. A secondary common crus is present in Arundelemys

724 dardeni (Fig. 6B), but the course of the lateral semicircular duct can be approximated in the

725 dorsal region as a weak imprint in the wall of the secondary common crus. The fenestra ovalis

726 shows as a larger, subcircular plane in the 3D model (Fig. 6A), and the fenestra perilymphatica

727 has the usual shape and position in the posterior surface of the lagena area (Fig. 6B). The

728 differences in labyrinth shape between Arundelemys dardeni and Pleurosternon moncayensis on

729 one side and Uluops uluops on the other cannot be easily functionally interpreted for the time

730 being, and undermine the hypothesis of Pérez-García et al. (2021) that the labyrinth shape of 
731 pleurosternids is indicative of their freshwater aquatic ecology. It is none the less interesting to

732 note significant shape disparity among relatively closely related species with probable similar

733 ecologies, which highlights that labyrinth ecomorphology is best interpreted in a quantitative

734 comparative framework (Bronzati et al., in press).

735

\section{DISCUSSION}

737 Although this re-description of Arundelemys dardeni is based on the same material and CT scans

738 as the original description by Lipka et al. (2006), we re-interpret several features of the anatomy,

739 pertaining to distinct skull regions (skull roof, palate, braincase wall, internal arterial canals).

740 Our deviating interpretations are backed up by digital renderings of the skull from CT data,

741 although some re-interpretations, such as the anterior pterygoid shape, resulted from disagreeing

742 that the interpretative cranial line drawings provided in the original study matched the

743 photographs shown in Lipka et al. (2006) and can thus be validated without the use of CT

744 technology. It is currently unclear how the updated anatomical interpretations provided here

745 affect phylogenetic assessments, but our interpretations certainly change character scorings.

746 Arundelemys dardeni was initially described as a basal paracryptodire, but primarily on the basis

747 of carotid features that received considerable re-interpretation since Lipka et al. (2006). Here, we

748 show that many features that allegedly show close correspondence between Arundelemys

749 dardeni and Compsemys victa (see Lipka et al., 2006), such as the extent of the temporal

750 emargination, were probably the result of misinterpretations. Instead, the more detailed account

751 of the cranial anatomy of Arundelemys dardeni given here shows some intriguing similarities

752 with Late Jurassic pleurosternids (e.g. position of anterior foramina for the abducens nerve,

753 presence of a well-developed carotid pit), although many differences to pleurosternids are also 
754 clear, for instance in the absence of secondary basioccipital tubera formed by posterior

755 parabasisphenoid processes. Many similarities to baenids are apparent as well, including the

756 probable early baenid Trinitichelys hiatti. This is for instance the case in the shared presence of a

757 ventral process of the jugal that nearly contacts the labial margin of the maxilla, a distinct lingual

758 ridge that is better developed near the contact of the maxilla with the vomer, a straight

759 basisphenoid-basioccipital suture, extensive contact of the pterygoid with the exoccipital, the

760 clear absence of a canal for the palatine artery (which is present in the pleurosternid Uluops

761 uluops but not Pleurosternon bullockii). Many of the recently observed cranial features of

762 paracryptodires have yet to be integrated into systematic work as phylogenetic characters, and

763 this paper provides additional comparative information to do that. This includes our attempt at

764 documenting and homologizing cranial scutes for paracryptodires. Scute sulci are often not

765 visible in non-baenid paracryptodires due to intense skull sculpturing (e.g. Uluops uluops), but

766 the retained pattern in Arundelemys dardeni might help in elucidating paracryptodiran

767 relationships among global turtle phylogeny, as it represents a thus far unused set of anatomical

768 characters and may provide novel signals.

769

770 CONCLUSIONS

771 The cranial anatomy of Arundelemys dardeni is re-interpreted and we offer differing views to

772 those provided in the initial description of the only available skull. Instead of having a largely

773 completely preserved skull roof with extreme emarginations and dorsally completely exposed

774 supraoccipital and prootics, we interpret Arundelemys dardeni as missing significant portions of

775 the dorsal skull roof formed by the parietals, postorbitals, and supraoccipital. These and other

776 changes in anatomical interpretation have no effect on the paracryptodiran affinities of 
777 Arundelemys dardeni, but the detailed description and comparative statements offered in our

778 work may help to refine its phylogenetic position within the group. Additionally, we provide a

779 description and homology interpretation of cranial scutes for Arundelemys dardeni. Cranial

780 scutes are common in turtles and symplesiomorphically present in Arundelemys dardeni. As

781 such, the scute pattern, which cannot be evaluated for all paracryptodires due to extensive skull

782 sculpturing in many species, may provide future phylogenetic information for global

783 paracryptodiran relationships.

784

785 INSTITUTIONAL ABBREVIATION

786 DORCM Dorset County Museum, Dorchester, United Kingdom.

787 USNM United States National Museum, Smithsonian Institution National Museum of

788 Natural History, Washington, D.C., USA.

789

790 ACKNOWLEDGEMENTS

791 We thank Donald Brinkman for initially sharing the CT scan, and Matthew Colbert for clarifying

792 some scanning parameters as well as initially conducting the CT scan on which this work is

793 based. We than reviewers Adán Pérez-García and Gabriel Ferreira for their excellent comments

794 that helped improving this paper, as well as the editor Mark Young. The work is supported by a 795 grant from the Swiss National Science Foundation (SNF 200021_178780/1).

796

797 REFERENCES 
798 Brinkman DB. 2003. Anatomy and systematics of Plesiobaena antiqua (Testudines; Baenidae)

799 from the mid-Campanian Judith River Group of Albert, Canada. Journal of Vertebrate

$800 \quad$ Paleontology 23(1):146-155.

801 Brinkman DB, Peng J-H. 1993. New material of Sinemys (Testduines, Sinemydidae) from the

802 Early Cretaceous of China. Canadian Journal of Earth Sciences 30:2139-2152.

803 Brinkman DB, Wu X-C. 1999. The skull of Ordosemys, an Early Cretaceous turtle from Inner

804 Mongolia, People's Republic of China, and the interrelationships of Eucryptodira (Chelonia, 805 Cryptodira). Paludicola 2(2):134-147.

806 Bronzati M, Benson RBJ. Evers SW, Ezcurra MD, Cabreira SF, Choiniere J, Dollman KN, 807 Pauliana-Carabajal A, Radermacher V, Roberto-da-Silva L, Sobral G, Stocker MR, 808 Witmer LM, Langer MC, Nesbitt SJ. 2021. Deep evolutionary diversification of 809 semicircular canals in archosaurs. Current Biology 31:1-10.

810 Evans J, Kemp TS. 1975. The cranial morphology of a new Lower Cretaceous turtle from

811 Southern England. Palaeontology 18(1):25-40.

812 Evans J, Kemp TS. 1976. A new turtle skull from the Purbeckian of England and a note on the 813 early dichotomies of cryptodire turtles. Palaeontology 19(2):317-324.

814 Evers SW. 2021. Project: Arundelemys dardeni (Paracryptodira) full cranial segmentation.

815 MorphoSource. https://www.morphosource.org/projects/000351178

816 Evers SW, Benson RBJ. 2019. A new phylogenetic hypothesis of turtles with implications for

817 the timing and number of evolutionary transitions to marine lifestyles in the group.

818 Palaeontology 62(1):93-134. 
819 Evers SW, Joyce WG. 2020. A re-description of Sandownia harrisi (Testudinata: Sandownidae)

820 from the Aptian of the Isle of Wight based on computed tomography scans. Royal Society

$821 \quad$ Open Science 7:191936.

822 Evers SW, Barrett PM, Benson RBJ. 2019. Anatomy of Rhinochelys pulchriceps

823 (Protostegidae) and marine adaptation during the early evolution of chelonioids. PeerJ

$824 \quad 7: e 6811$.

825 Evers SW, Neenan JM, Ferreira GS, Werneburg I, Barrett PM, Benson RBJ. 2019.

826 Neurovascular anatomy of the protostegid turtle Rhinochelys pulchriceps and comparisons of

827 membranous and endosseous labyrinth shape in an extant turtle. Zoological Journal of the

828 Linnean Society 187:800-828.

829 Evers SW, Rollot Y, Joyce WG. 2020. Cranial osteology of the Early Cretaceous turtle

830 Pleurosternon bullockii (Paracryptodira: Pleurosternidae). PeerJ 8:e9454.

831 Ferreira GS, Lautenschlager S, Evers SW, Pfaff C, Kriwet J, Raselli I, Werneburg I. 2020.

832 Feeding biomechanics suggests progressive correlation of skull architecture and neck

833 evolution in turtles. Scientific Reports 10:5505.

834 Gaffney ES. 1972. The systematics of the North American family Baenidae (Reptilia,

835 Cryptodira). Bulletin of the American Museum of Natural History 147(5):241-320.

836 Gaffney ES. 1975. A phylogeny and classification of the higher categories of turtles. Bulletin of

837 the American Museum of Natural History 155(5):387-436.

838 Gaffney ES. 1979. Comparative cranial morphology of Recent and fossil turtles. Bulletin of the

839 American Museum of Natural History 164(2):65-376. 
840 Gaffney ES. 1979. The cranial morphology of the extinct horned turtle, Meiolania platyceps,

841 from the Pleistocene of the Lord Howe Island, Australia. Bulletin of the American Museum of

$842 \quad$ Natural History 175(4):361-480.

843 Gaffney ES. 1990. The comparative osteology of the Triassic turtle Proganochelys. Bulletin of

844 the American Museum of Natural History 194:1-263.

845 Georgi JA, Sipla JS. 2008. Comparative and functional anatomy of balance in aquatic reptiles

846 and birds. In: Thewissen JHM, Nummela S, eds. Sensory Evolution on the Threshold,

847 Adaptations in Secondarily Aquatic Vertebrates. Berkeley: University of California Press,

$848 \quad 133-256$.

849 Hooks III GE. 1998. Systematic revision of the Protostegidae, with a redescription of

850 Calcarichelys gemma Zangerl, 1953. Journal of Vertebrate Paleontology 18(1):85-98.

851 Joyce WG, Rollot Y. 2020. An alternative interpretation of Peltochelys duchastelii as a

852 paracryptodire. Fossil Record 23(1):83-93.

853 Joyce WG, Chapman S, Moody RTJ, Walker CA. 2011. The skull of the solemydid turtle

854 Helochelydra nopscai from the Early Creatceous of the Isle of Wight (UK) and a review of

855 Solemydidae. Special Papers in Palaeontology 86:75-97.

856 Khosatzky LI. 1997. Big turtle of the Late Cretaceous of Mongolia. Russian Journal of

857 Herpetology 4(2): 148-154.

858 Klein IT. 1760. Klassification und kurze Geschichte der vierfüßigen Thiere (translated by Behn $859 \quad F D)$. Lübeck: Jonas Schmidt.

860 Li D-Q, Zhou C-F, Li L, Yang J-T, Li L, Rabi M. 2019. The sinemydids turtle Ordosemys

861 from the Lower Cretaceous Mengyin Formation of Shandong, China and its implication for

862 the age of the Luohandong Formation of the Ordos Basin. PeerJ 7:e6229. 
863 Larson DW, Longrich NR, Evans DC, Ryan MJ. 2013. A new species of Neurankylus from 864 the Milk River Formation (Cretceous: Santonian) of Alberta, Canada, and a revision of the 865 type species N. maximus. In: Brinkman DB, Holroyd PA, Gardner JD, eds. Morphology and 866 evolution of turtles. Dordrecht: Springer Science + Business Media, 389-405.

867 Lautenschlager S, Ferreira GS, Werneburg I. 2018. Sensory evolution and ecology of early 868 turtles revealed by digital endocranial reconstructions. Frontiers in Ecology and Evolution $869 \quad 6: 7$.

870 Lipka TR, Therrien F, Weishampel DB, Jamniczky HA, Joyce WG, Colbert MW, 871 Brinkman DB. 2006. A new turtle from the Arundel Clay Facies (Potomac Formation, Early 872 Cretaceous) of Maryland, U.S.A. Journal of Vertebrate Paleontology 26(2):300-307.

873 Lively JR. 2015. A new species of baenid turtle from the Kaiparowits Formation (Upper 874 Cretaceous, Campanian) of southern Utah. Journal of Vertebrate Paleontology 875 35(6):e1009084.

876 Lyson TR, Joyce WG. 2009a. A new species of Palatobaena (Testudines: Baenidae) and a 877 maximum parsimony and Bayesian phylogenetic analysis of Baenidae. Journal of $878 \quad$ Paleontology 83(3):457-470.

879 Lyson TR, Joyce WG. 2009b. A revision of Plesiobaena (Testudines: Baenidae) and an 880 assessment of baenid ecology across the K/T boundary. Journal of Paleontology 83(6):833$881 \quad 853$.

882 Lyson TR, Joyce WG. 2011. Cranial anatomy and phylogenetic placement of the enigmatic 883 turtle Compsemys victa Leidy, 1856. Journal of Paleontology 85(4):749-801. 
884 Lyson TR, Joyce WG, Knauss GE, Pearson DA. 2011. Boremys (Testudines, Baenidae) from

885 the latest Cretaceous and Early Paleocene of North Dakota: An 11-million-year range

886 extension and an additional K/T survivor. Journal of Vertebrate Paleontology 31(4):729-737.

887 Lyson TR, Joyce WG, Lucas SG, Sullivan RM. 2016. A new baenid turtle from the early

888 Paleocene (Torrejonian) of New Mexico and a species-level phylogenetic analysis of

889 Baenidae. Journal of Paleontology 90(2):305-316.

890 Lyson TR, Sayler JL, Joyce WG. 2019. A new baenid turtle, Saxochelys gilberti, gen. et sp.

891 nov., from the uppermost Cretaceous (Maastrichtian) Hell Creek Formation: sexual

892 dimorphism and spatial niche partitioning within the most speciose group of Late Cretaceous

893 turtles. Journal of Vertebrate Paleontology 39(4):e162428.

894 Neenan JM, Reich T, Evers SW, Druckenmiller PS, Voeten DFAE, Choiniere JN, Barrett

895 PM, Pierce SE, Benson RBJB. 2017. Evolution of the sauropterygian labyrinth with

896 increasingly pelagic lifestyles. Current Biology 27:3852-3858.

897 Pérez-García A, Espílez E, Mampel L, Alcalá L. 2015. A new European Albian turtle that

898 extends the known stratigraphic range of Pleurosternidae (Paracryptodira). Cretaceous

$899 \quad$ Research 55:74-83.

900 Pérez-García A, Martín-Jiménez M, Aurell M, Canudo JI, Castanera D. 2021. A new

901 Iberian pleurosternid (Jurassic-Cretaceous transition, Spain) and first neuroanatomical study

902 of this clade of stem turtles. Historical Biology. doi: 10.1080/08912936.2021.1910818

903 Rabi M, Zhou C-F, Wings O, Ge S, Joyce WG. 2013. A new xinjiangchelyid turtle from the

904 Middle Jurassic of Xinjiang, China and the evolution of the basipterygoid process in

905 Mesozoic turtles. BMC Evolutionary Biology 13:1-28. 
906 Rabi M, Sukhanov VB, Egorova VN, Danilov I, Joyce WG. 2014. Osteology, relationships, 907 and ecology of Annemys (Testudines, Eucryptodira) from the Late Jurassic of Shar Teg, 908 Mongolia, and phylogenetic definitions for Xinjiangchelyidae, Sinemydidae, and 909 Macrobaenidae. Journal of Vertebrate Paleontology 34(2):327-352.

910 Rollot Y, Lyson TR, Joyce WG. 2018. A description of the skull of Eubaena cephalica (Hay, 911 1904) and new insights into the cranial circulation and innervation of baenid turtles. Journal 912 of Vertebrate Paleontology 38(3): 1474886.

913 Rollot Y, Evers SW, Joyce WG. in press. A redescription of the Late Jurassic turtle Uluops 914 uluops and a new phylogenetic hypothesis of Paracryptodira. Swiss Journal of Palaeontology.

915 Rollot Y, Evers SW, Joyce WG. 2021b. A review of the cartod artery and facial nerve canal $916 \quad$ system in extant turtles. PeerJ 8: 10475.

917 Simpson GG. 1938. Crossochelys, Eocene horned turtles from Patagonia. Bulletin of the 918 American Museum of Natural History 74:221-254.

919 Smith HF, Hutchison JH, Townsend KEB, Adrain B, Jager D. 2017. Morphological

920 variation, phylogenetic relationships, and geographic distribution of the Baenidae

921 (Testudines), based in new specimens from the Uinta Formation (Uinta Basin), Utah (USA).

$922 \quad$ PLOS ONE 12:e0180574.

923 Sterli J. 2015. A review of the fossil record of the Gondwanan turtles of the clade

924 Meiolaniformes. Bulletin of the Peabody Museum of Natural History 56(1):21-45.

925 Sterli J, Joyce WG. 2007. The cranial anatomy of the Early Jurassic turtle Kayentachelys aprix. 926 Acta Palaeontologica Polonica 52(4):675-694. 
927 Sterli J, de la Fuente MS. 2013. New evidence from the Palaeocene of Patagonia (Argentina)

928 on the evolution and palaeo-biogegraphy of Meiolaniformes (Testudinata, new taxon name).

929 Journal of Systematic Palaeontology 11(7):835-852.

930 Sukhanov VB. 2000. Mesozoic turtles of middle and central Asia. In: Benton MJ, Shiskin MA, 931 Unwin DM, Kurochkin EN, eds. The Age of Dinosaurs in Russia and Mongolia. Cambridge: 932 Cambridge University Press, 309-367.

933 Tong H, Nakri W, Buffetaut E, Suteethorn S, Suteethorn V, Chantasit P, Claude J. 2019. 934 Kalasinemys, a new xinjiangchelyid turtle from the Late Jurassic of NE Thailand. Geological 935 Magazine 156(10): 1645-1656.

936 Walsh SA, Barrett PM, Milner AC, Manley G, Witmer LM. 2009. Inner ear anatomy is a 937 proxy for deducing auditory capability and behavious in reptiles and birds. Proceedings of the 938 Royal Society B: Biologial Sciences 276:1355-1360.

939 Zhou C-F, Rabi M, Joyce WG. 2014. A new specimen of Manchurochelys manchoukuoensis 940 from the Early Cretaceozs Jehol Biota of Chifeng, Inner Mongolia China and the hylogeny of 941 Cretaceous basal eucryptodiran turtles. BMC Evolutionary Biology 14(77):1-16.

942

943

944

945

946

947

948

949

Figure 1 Three dimensional renderings of the cranium of Arundelemys dardeni (USNM 497740). A, dorsal view. B, ventral view. C, left lateral view. D, right lateral view. E, anterior view. F, posterior view. Abbreviations: boc, basioccipital; cap, carotid pit; epi, epipterygoid; ex, exoccipital, f, frontal; fpp, foramen palatinum posterius; fprp, foramen prepalatinum; fst, foramen stapedio-temporale; ica, incisura columella auris; j, jugal; lir, lingual ridge; mdaf, 
950 mandibular artery foramen; mx, maxilla; $\mathrm{n}$, nasal; op, opisthotic; pa, parietal; pal, palatine; pbs,

951 parabasisphenoid; pm, premaxilla; po, postorbital; pr, prootic; prf, prefrontal; pt, pterygoid; pte,

952 processus pterygoideus externus; q, quadrate; soc, supraoccipital; tf, trigeminal foramen; v,

953 vomer. Note that bone labels are in bold. Scale bars equal $10 \mathrm{~mm}$.

954

955 Figure 2 Cranial scutes of Arundelemys dardeni (USNM 497740). A, Three dimensional

956 rendering of the cranium in dorsal view. B, interpretative line drawing of A. C, Three

957 dimensional rendering of the cranium in left lateral view. D, interpretative line drawing of C.

958 Note that sutural lines are thin black lines in B \& D, whereas thick lines are scute sulci, which

959 are labelled with capital letters (following the nomenclature of Sterli \& de la Fuente, 2013).

960 Abbreviations: epi, epipterygoid; f, frontal; j, jugal; mx, maxilla; n, nasal; op, opisthotic; pa,

961 parietal; pm, premaxilla; po, postorbital; pr, prootic; prf, prefrontal; pt, pterygoid; q, quadrate;

962 soc, supraoccipital. Scale bar equals $10 \mathrm{~mm}$.

963

964 Figure 3 Proposed homology of cranial scutes for selected stem turtles. A, Proganochelys

965 quenstedtii in dorsal view (based on Gaffney, 1990; Sterli et al., 2013). B, Mongolochelys

966 efremovi in dorsal (top) and lateral (bottom) view (based on Khosatzky, 1997; Sukhanov, 2000;

967 Sterli et al., 2013). C, Meiolania platyceps in dorsal (top) and lateral (bottom) views (modified

968 from Gaffney 1983; Sterli et al., 2013). Note that D and H scutes are switched with regard to

969 previous figures of Meiolania. D, Arundelemys dardeni in lateral (top) and dorsal (bottom) view.

970 Note that skull was mirrored for comparison. E, Ordosemys leios in dorsal view (based on Li et

971 al., 2019). Note additional identification of H scute. F, Annemys levensis in dorsal view

972 (modified from Rabi et al., 2014). Note changes in D and H scute position and midline contact of 
973 anterior F scute. Capital letters labels indicate scute names. Skulls are not to scale. Note that

974 fossil preservation did not allow identification of scutes for lateral skull surfaces of turtles shown 975 in A, E-F.

976

977 Figure 4 Three dimensional renderings of the nasal cavity and orbitotemporal region of 978 Arundelemys dardeni (USNM 497740). A, medial view on left half of anterior cranium, 979 showing the inside of the nasal cavity. B, posterolateral view of cranium, viewing into the 980 temporal fossa. Abbreviations: boc, basioccipital; crcr, crista cranii; dpp, descending process of 981 parietal; epi, epipterygoid; ex, exoccipital; f, frontal; fja, foramen jugulare anterius; ica, incisura 982 columella auris; ina, internal naris; j, jugal; jmp, jugal medial process; lar, labial ridge; lir, 983 lingual ridge; mdaf, mandibular artery foramen; $\mathrm{mr}$, medial ridge of prefrontal; mx, maxilla; $\mathrm{n}$, 984 nasal; op, opisthotic; pa, parietal; pm, premaxilla; po, postorbital; pppt, posterior process of 985 pterygoid; prf, prefrontal; pro, prootic; pte, processus pterygoideus externus; q, quadrate; soc, 986 supraoccipital; sot, septum orbitotemporale; tf, trigeminal foramen; vr, ventral ridge of nasal.

987 Scale bar equals $10 \mathrm{~mm}$.

988

989

990

Figure 5 Three dimensional renderings of the basicranial region of Arundelemys dardeni

(USNM 497740). A, pterygoids and parabasisphenoid in ventral view. B, as A, but bones

991

rendered transparent and carotid artery and facial nerve models added. $\mathbf{C}$, anterodorsal view of

992 pterygoids, parabasisphenoid, carotid artery, facial nerve, and abducens nerve. Abbreviations:

993 app, anterior process of pterygoid; cap, carotid pit; cera, cerebral artery; faccb, foramen anterius

994 canalis carotici basisphenoidalis; faf, fossa acustico-facialis; fdnv, foramen distalis nervi vidiani;

995 facnv, foraman anterius canalis nervi vidiani; fpcnv, foramen posterius canalis nervi vidiani; gg, 
996 geniculate ganglion; ica, internal carotid artery; pbs, parabasisphenoid; pt, pterygoid; pte, 997 processus pterygoideus externus; rbp, retractor bulbi pit; scav, sulcus cavernosus; tf, trigeminal 998 foramen; VI, abducens nerve; VII, facial nerve; VIIhyo, hyomandibular branch of the facial 999 nerve; VIIvi, vidian branch of the facial nerve; VIII, acoustic nerve. Scale bar equals $10 \mathrm{~mm}$. 1000

1001 Figure 6 Three dimensional renderings of left labyrinth of Arundelemys dardeni (USNM 1002 497740). A, lateral view. B, posterior view. C, dorsal view. Abbreviations: asc, anterior 1003 semicircular canal; cc, common crus; fov, fenestra ovalis; fpl, fenestra perilymphatica; lsc, lateral 1004 semicircular canal; psc, posterior semicircular canal; scc, secondary common crus. 


\section{Figure 1}

Three dimensional renderings of the cranium of Arundelemys dardeni (USNM 497740)

A, dorsal view. B, ventral view. C, left lateral view. D, right lateral view. E, anterior view. F, posterior view. Abbreviations: boc, basioccipital; cap, carotid pit; epi, epipterygoid; ex, exoccipital, f, frontal; fpp, foramen palatinum posterius; fprp, foramen prepalatinum; fst, foramen stapedio-temporale; ica, incisura columella auris; j, jugal; lir, lingual ridge; mdaf, mandibular artery foramen; mx, maxilla; n, nasal; op, opisthotic; pa, parietal; pal, palatine; pbs, parabasisphenoid; pm, premaxilla; po, postorbital; pr, prootic; prf, prefrontal; pt, pterygoid; pte, processus pterygoideus externus; q, quadrate; soc, supraoccipital; tf, trigeminal foramen; $v$, vomer. Note that bone labels are in bold. Scale bars equal $10 \mathrm{~mm}$. 

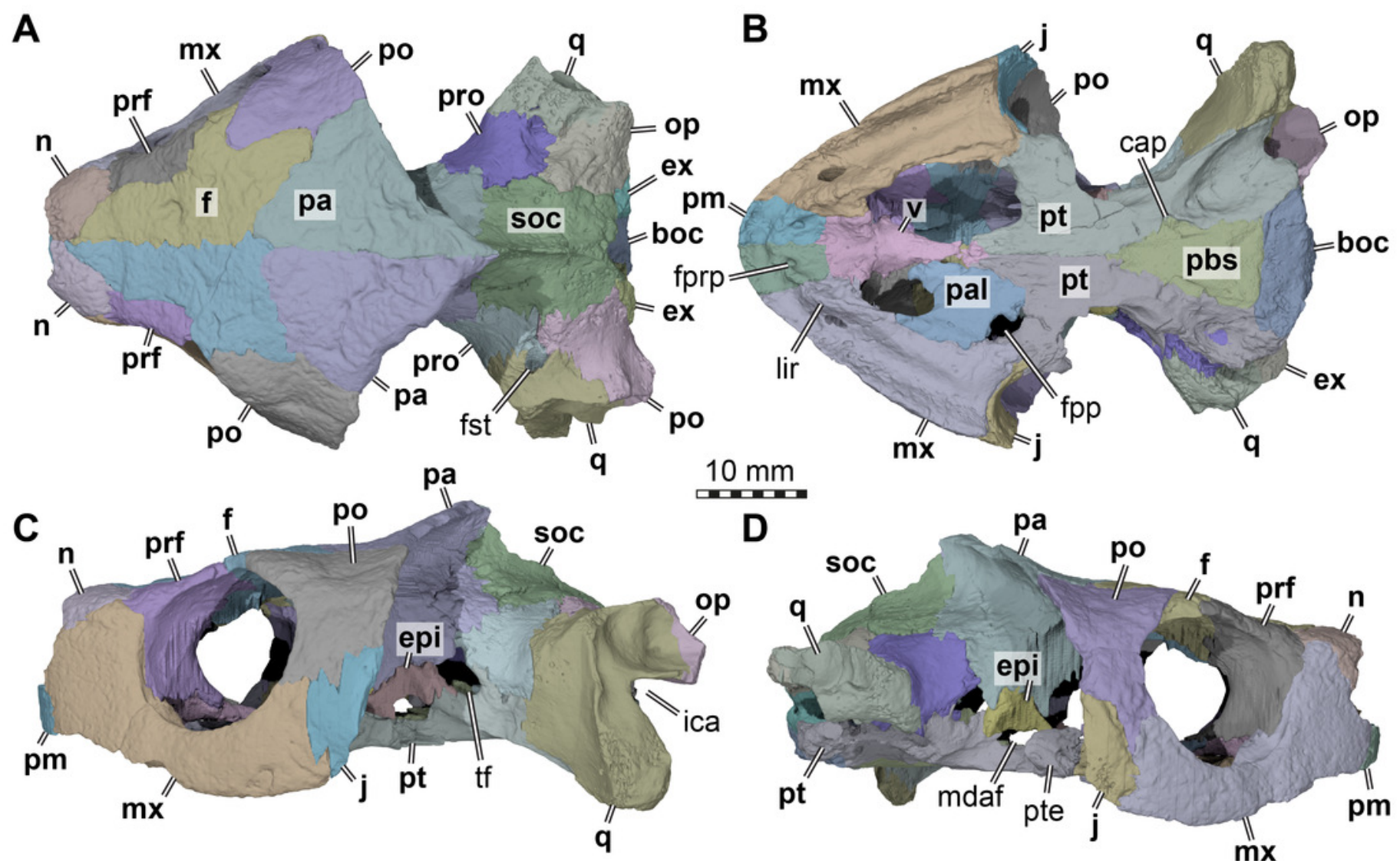

E

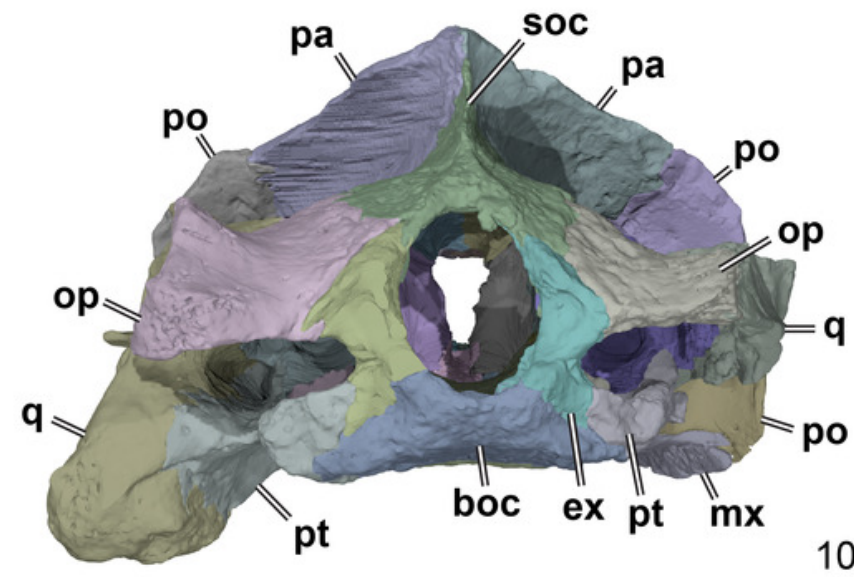

F

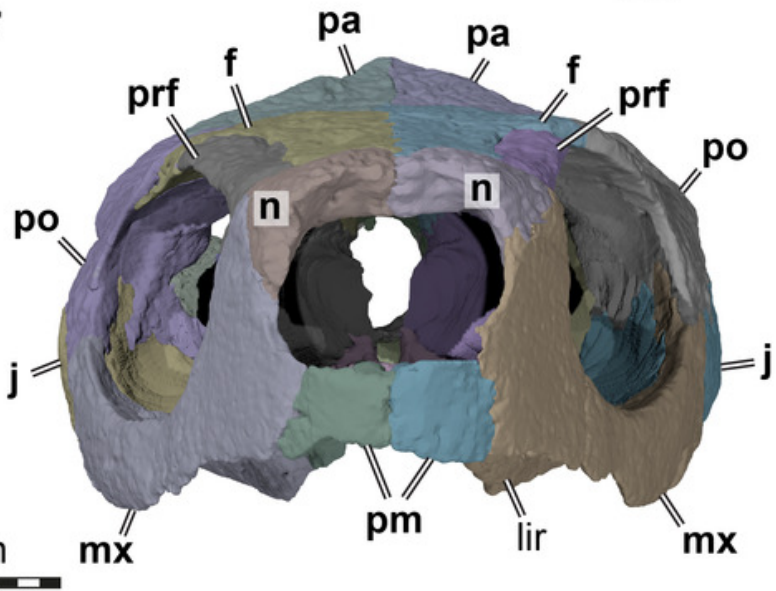




\section{Figure 2}

Cranial scutes of Arundelemys dardeni (USNM 497740)

A, Three dimensional rendering of the cranium in dorsal view. B, interpretative line drawing of A. C, Three dimensional rendering of the cranium in left lateral view. D, interpretative line drawing of $C$. Note that sutural lines are thin black lines in $B \& D$, whereas thick lines are scute sulci, which are labelled with capital letters (following the nomenclature of Sterli \& de la Fuente, 2013). Abbreviations: epi, epipterygoid; f, frontal; j, jugal; mx, maxilla; n, nasal; op, opisthotic; pa, parietal; pm, premaxilla; po, postorbital; pr, prootic; prf, prefrontal; pt, pterygoid; q, quadrate; soc, supraoccipital. Scale bar equals $10 \mathrm{~mm}$.

A

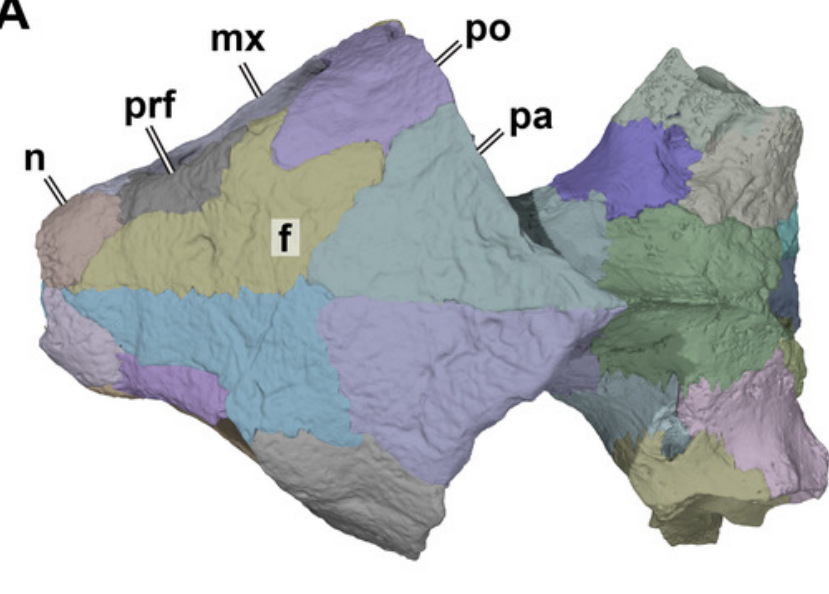

C

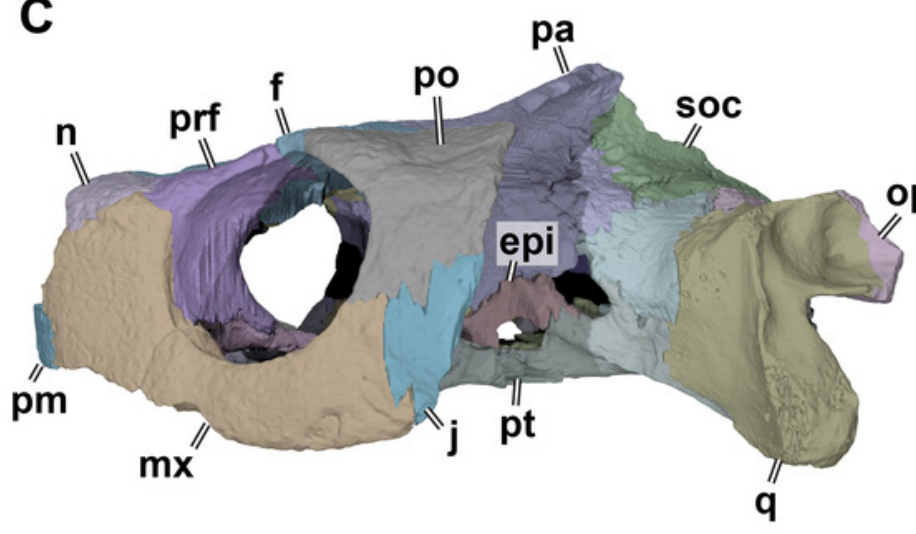

B

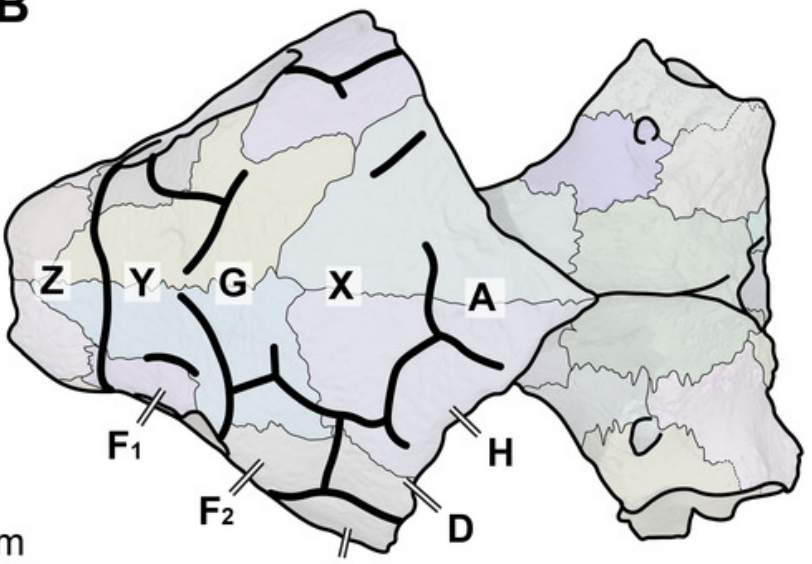

$F_{3}$

D

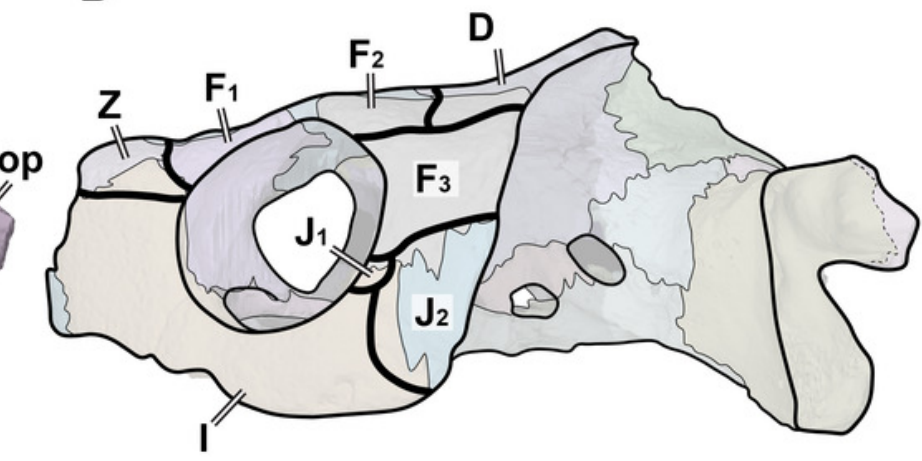




\section{Figure 3}

Proposed homology of cranial scutes for selected stem turtles

A, Proganochelys quenstedtii in dorsal view (based on Gaffney, 1990; Sterli et al., 2013). B, Mongolochelys efremovi in dorsal (top) and lateral (bottom) view (based on Khosatzky, 1997;

Sukhanov, 2000; Sterli et al., 2013). C, Meiolania platyceps in dorsal (top) and lateral (bottom) views (modified from Gaffney 1983; Sterli et al., 2013). Note that D and H scutes are switched with regard to previous figures of Meiolania. D, Arundelemys dardeni in lateral (top) and dorsal (bottom) view. Note that skull was mirrored for comparison. E, Ordosemys leios in dorsal view (based on Li et al., 2019). Note additional identification of H scute. F, Annemys levensis in dorsal view (modified from Rabi et al., 2014). Note changes in D and $\mathrm{H}$ scute position and midline contact of anterior F scute. Capital letter labels indicate scute names. Skulls are not to scale. Note that fossil preservation did not allow identification of scutes for lateral skull surfaces of turtles shown in A, E-F. 
A

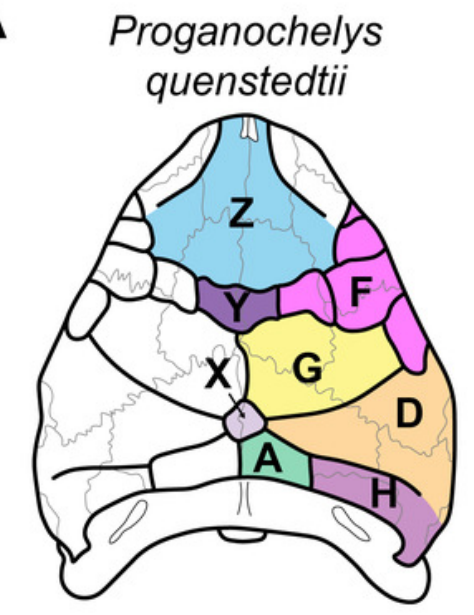

D
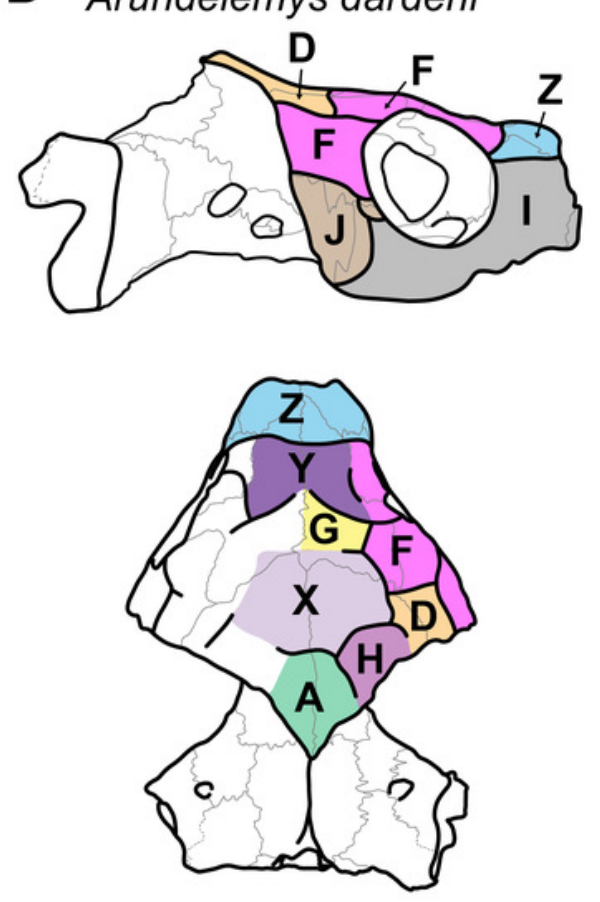

B Mongolochelys efremovi
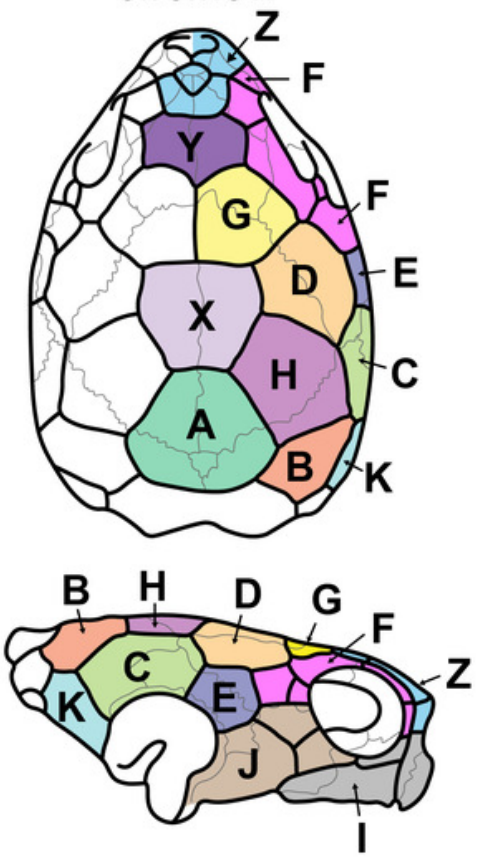

$\mathbf{E}$
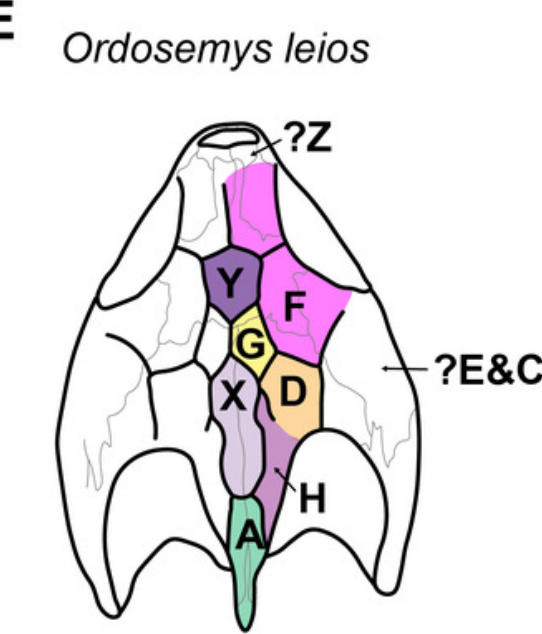

C Meiolania platyceps
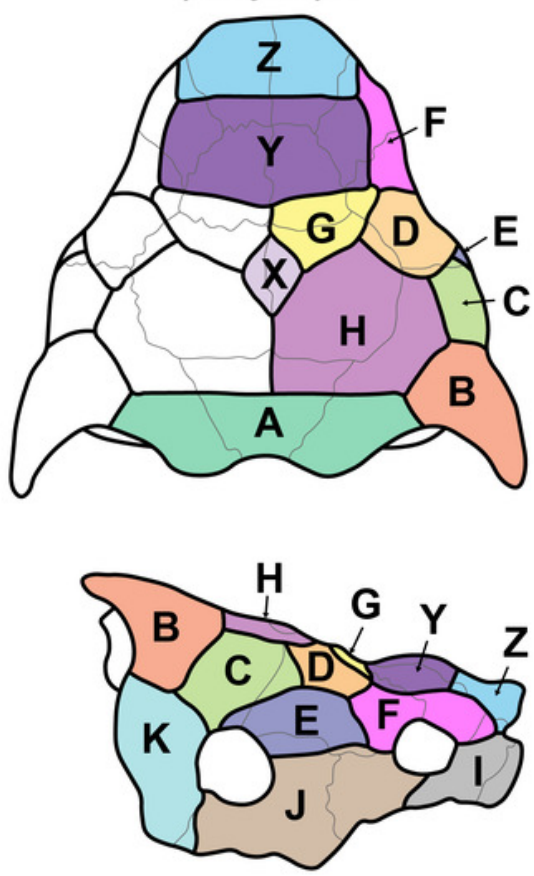

$\mathbf{F}$

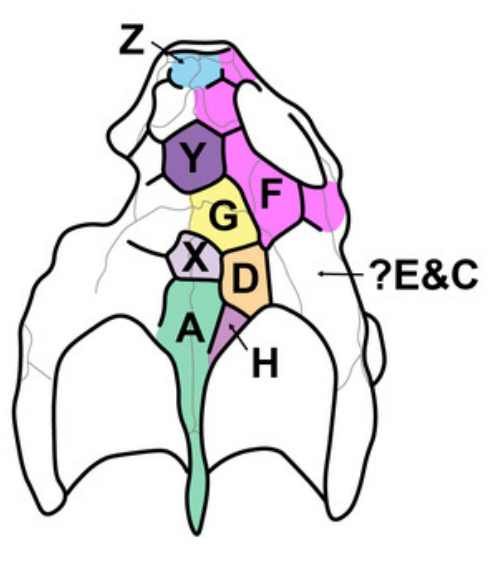




\section{Figure 4}

Three dimensional renderings of the nasal cavity and orbitotemporal region of Arundelemys dardeni (USNM 497740)

A, medial view on left half of anterior cranium, showing the inside of the nasal cavity. B, posterolateral view of cranium, viewing into the temporal fossa. Abbreviations: boc, basioccipital; crcr, crista cranii; dpp, descending process of parietal; epi, epipterygoid; ex, exoccipital; f, frontal; fja, foramen jugulare anterius; ica, incisura columella auris; ina, internal naris; j, jugal; jmp, jugal medial process; lar, labial ridge; lir, lingual ridge; mdaf, mandibular artery foramen; mr, medial ridge of prefrontal; mx, maxilla; $n$, nasal; op, opisthotic; pa, parietal; pm, premaxilla; po, postorbital; pppt, posterior process of pterygoid; prf, prefrontal; pro, prootic; pte, processus pterygoideus externus; q, quadrate; soc, supraoccipital; sot, septum orbitotemporale; tf, trigeminal foramen; vr, ventral ridge of nasal. Scale bar equals $10 \mathrm{~mm}$.

A

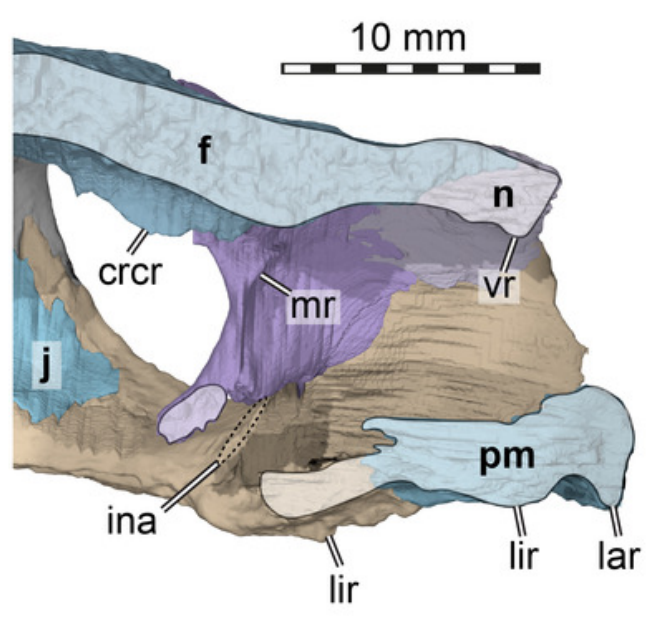

B

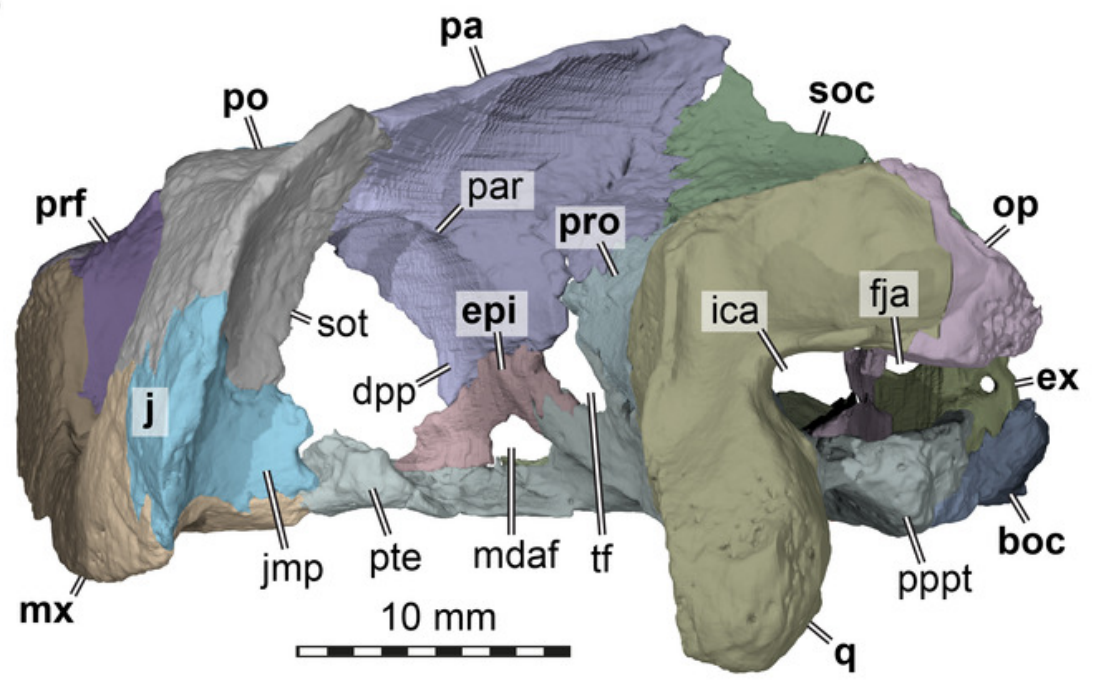




\section{Figure 5}

Figure 4 Three dimensional renderings of the basicranial region of Arundelemys dardeni (USNM 497740)

A, pterygoids and parabasisphenoid in ventral view. B, as A, but bones rendered transparent and carotid artery and facial nerve models added. C, anterodorsal view of pterygoids, parabasisphenoid, carotid artery, facial nerve, and abducens nerve. Abbreviations: app, anterior process of pterygoid; cap, carotid pit; cera, cerebral artery; faccb, foramen anterius canalis carotici basisphenoidalis; faf, fossa acustico-facialis; fdnv, foramen distalis nervi vidiani; facnv, foraman anterius canalis nervi vidiani; fpcnv, foramen posterius canalis nervi vidiani; gg, geniculate ganglion; ica, internal carotid artery; pbs, parabasisphenoid; pt, pterygoid; pte, processus pterygoideus externus; rbp, retractor bulbi pit; scav, sulcus cavernosus; tf, trigeminal foramen; VI, abducens nerve; VII, facial nerve; VIIhyo, hyomandibular branch of the facial nerve; VIIvi, vidian branch of the facial nerve; VIII, acoustic nerve. Scale bar equals $10 \mathrm{~mm}$.

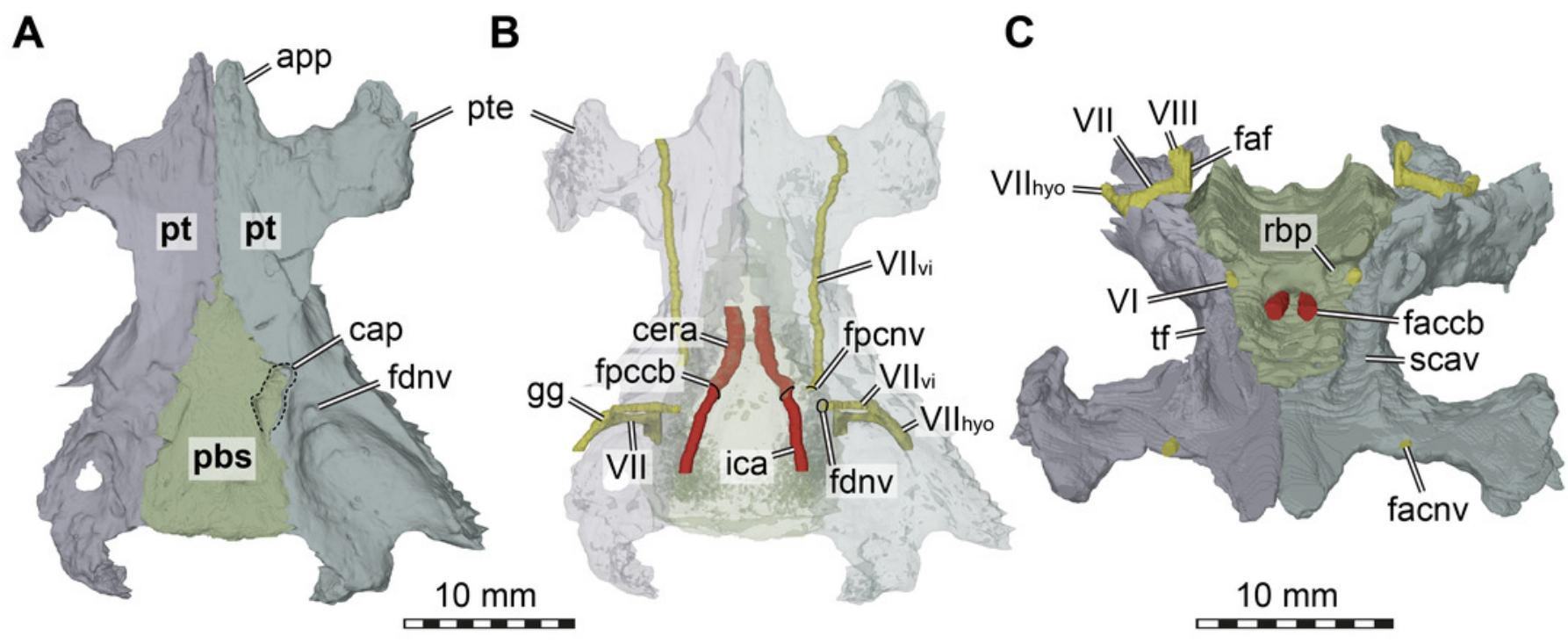




\section{Figure 6}

Three dimensional renderings of left labyrinth of Arundelemys dardeni (USNM 497740).

A, lateral view. B, posterior view. C, dorsal view. Abbreviations: asc, anterior semicircular canal; cc, common crus; fov, fenestra ovalis; fpl, fenestra perilymphatica; Isc, lateral semicircular canal; psc, posterior semicircular canal; scc, secondary common crus.
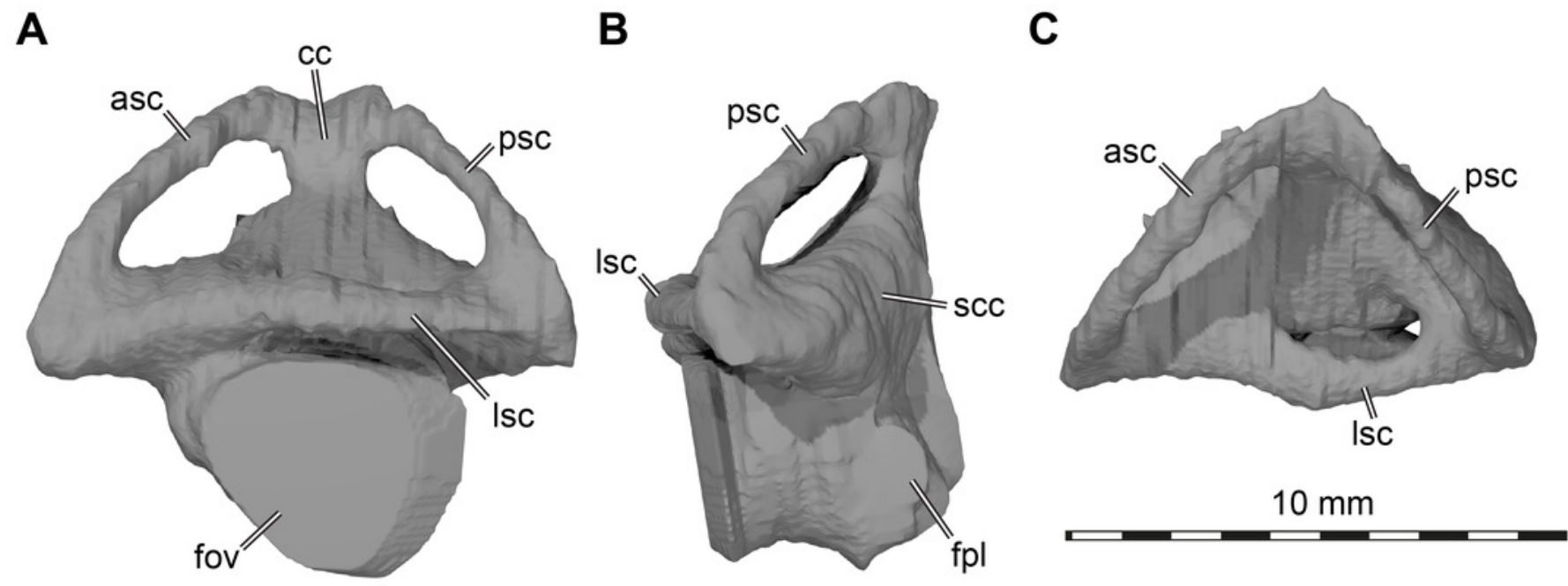